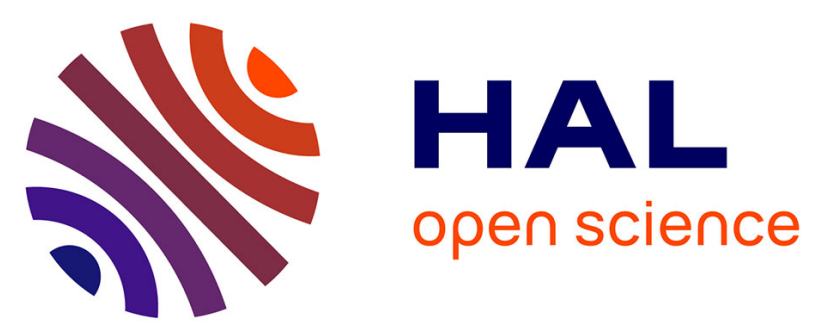

\title{
Gemcitabine versus Modified Gemcitabine: A Review of Several Promising Chemical Modifications.
}

Elodie Moysan, Guillaume Bastiat, Jean-Pierre Benoit

\section{To cite this version:}

Elodie Moysan, Guillaume Bastiat, Jean-Pierre Benoit. Gemcitabine versus Modified Gemcitabine: A Review of Several Promising Chemical Modifications.: Fluorinated lipid nanocapsules as oxygen sensor. Molecular Pharmaceutics, 2013, 10 (2), pp.430-44. 10.1021/mp300370t . inserm-00787112

\section{HAL Id: inserm-00787112 https://www.hal.inserm.fr/inserm-00787112}

Submitted on 1 Oct 2013

HAL is a multi-disciplinary open access archive for the deposit and dissemination of scientific research documents, whether they are published or not. The documents may come from teaching and research institutions in France or abroad, or from public or private research centers.
L'archive ouverte pluridisciplinaire HAL, est destinée au dépôt et à la diffusion de documents scientifiques de niveau recherche, publiés ou non, émanant des établissements d'enseignement et de recherche français ou étrangers, des laboratoires publics ou privés. 


\section{Gemcitabine versus modified gemcitabine: a review of several promising chemical modifications}

Elodie Moysan ${ }^{t, \ddagger}$, Guillaume Bastiat ${ }^{t, \ddagger}$ and Jean-Pierre Benoit ${ }^{t, \neq}$

\footnotetext{
${ }^{\dagger}$ LUNAM Université - Micro et Nanomédecines Biomimétiques, F-49933 Angers, France

${ }^{\ddagger}$ INSERM - U1066 IBS-CHU, F-49933 Angers, France
} 


\section{Abstract}

Gemcitabine, an anticancer agent which acts against a wide range of solid tumors, is known to be rapidly deaminated in blood to the inactive metabolite 2',2'difluorodeoxyuridine and to be rapidly excreted by the urine. Moreover, many cancers develop resistance against this drug, such as loss of transporters and kinases responsible for the first phosphorylation step. To increase its therapeutic levels, gemcitabine is administered at high dose $\left(1000 \mathrm{mg} / \mathrm{m}^{2}\right)$ causing sides effects (neutropenia, nausea...).To improve its metabolic stability, its cytotoxic activity and to limit the phenomena of resistance many alternatives have emerged,such as the synthesis of prodrugs. Modifying an anticancer agent is not new, paclitaxel or ara-C have been subjected to such changes. This review summarizes the various chemical modifications that can be found in $4-(N)$ - and 5 ' position of gemcitabine. They can provide (i) a protection against deamination, (ii) a better storage and (iii) a prolonged release in the cell, (iv) a possible use in case of deoxycytidine kinase deficiency and (v) transporters deficiency. These new gemcitabine based sysems have the potential to improve the clinical outcome of a chemotherapy strategy.

KEYWORDS : gemcitabine, prodrug, chemical modification, resistance, antitumor effect 


\section{Content}

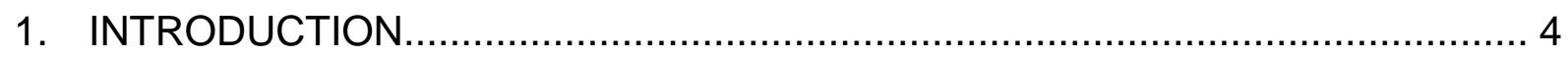

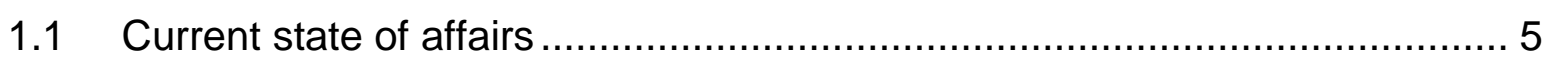

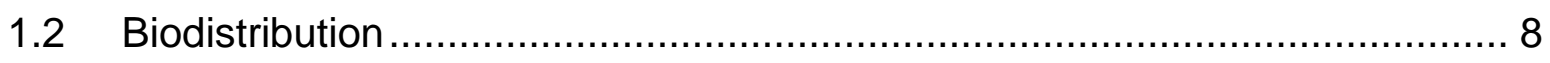

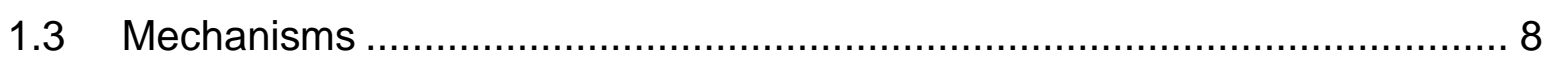

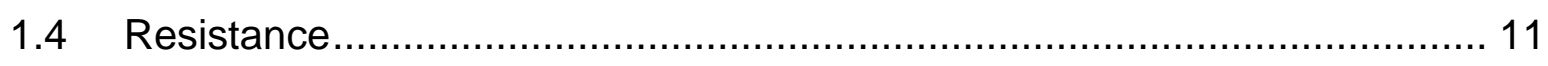

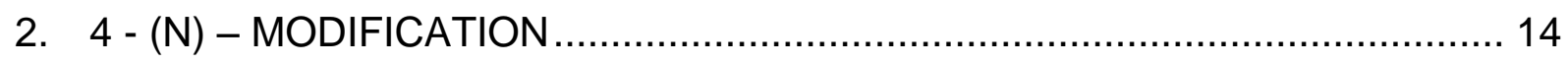

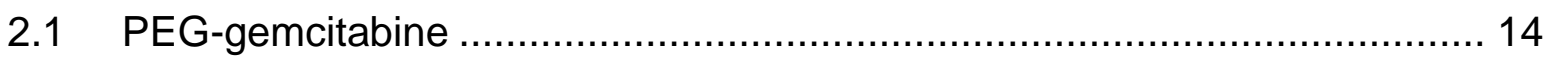

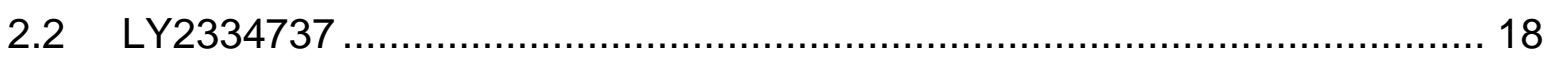

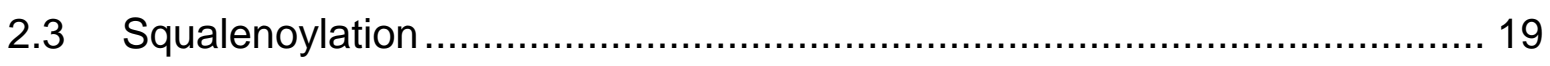

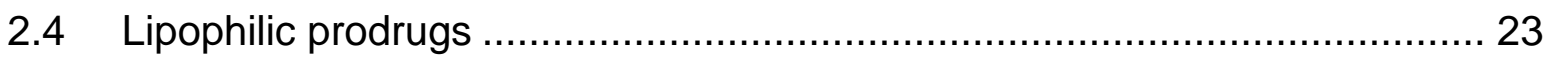

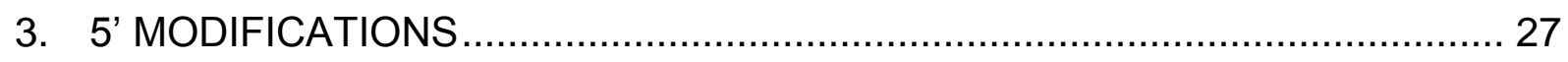

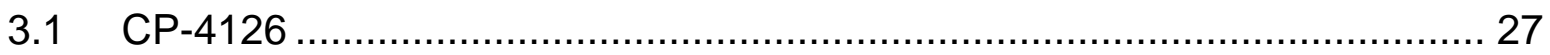

3.2 NEO6002

3.3 Phosphoramidate Gemcitabine …………...................................... 30

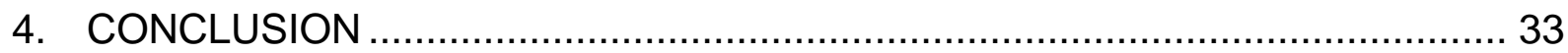

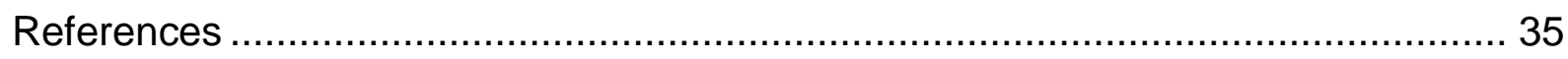




\section{INTRODUCTION}

Cancer is the leading cause of death in developed countries. A major reason for this high mortality is the failure of current treatment that is in part attributed to the phenomenon of resistance but is also due to ineffective treatment against metastases. Current treatment of cancer using chemotherapy is largely based on the use of nucleoside analogues. These molecules are designed to mimic natural pyrimidine and purine nucleosides. Gemcitabine is one of these nucleoside analogues.

Gemcitabine acts against a wide range of solid tumours such as pancreatic, nonsmall lung, breast and ovarian cancers. ${ }^{1-4}$ One of the major difficulties in cancer therapy is that tumours acquire resistance over time. This resistance is related to the functioning of gemcitabine. Gemcitabine is transported into cells by different transporters, such as hENT1, and a decreased expression of hENT1 is responsible for a lower level of activity of gemcitabine by blocking its uptake. ${ }^{5}$ Once in the cell, gemcitabine undergoes a series of phosphorylations in order to be active; the first of these is carried out by deoxycytidine deaminase (dCK). A low level of dCK is correlated with low gemcitabine cytotoxicity. ${ }^{6}$ Furthermore, gemcitabine is rapidly deaminated by cytidine deaminase (CDA) causing a short plasma half-life. ${ }^{7}$ Therefore, strategies that provide both enhanced transport and high metabolic bioevasion by chemical modification could potentially lead to new therapeutic strategies.

In this review we look at the pharmacological parameters of gemcitabine, its mode of action (which remains the same even with modified forms), and we describe the state of the art of various chemical modifications of gemcitabine, exclusively on 2 sites of the molecule (4-(N) and 5' sites, Figure 1), which have been carried out to improve 
its efficiency. A prodrug is a biologically-inactive derivative of a parent drug molecule that usually requires an enzymatic or chemical transformation within the body in order to release the active drug, and has improved delivery properties in comparison to the parent molecule. ${ }^{8}$ Drug modification has already been used with other anticancer drugs to overcome some disadvantages of the parent drug. For example, paclitaxel has been covalently attached to an acyl chain to obtain a lipophilic prodrug of paclitaxel to increase its encapsulation in lipid emulsions. ${ }^{9}$ Another example is Ara-C, modified to facilitate Ara-C uptake and prolong its retention in the cell by grafting a fatty-acid chain at the $5^{\prime}$ position of the nucleoside. ${ }^{10}$

\section{$\underline{\text { Insert Figure } 1 .}$}

In the 4-( $(M)$ - position of gemcitabine, we will describe modifications with PEG, with valproic acid, with 1,1',2-tris-nor-squalenoic acid (squalene), and with valeroyl, heptanoyl, lauroyl and stearoyl linear acyl derivatives. In the 5' position, grafting with elaidic acid, with cardiolipin, and a series of phosphoramidates will be reported. All these new gemcitabine-based molecules have the potential to improve the clinical outcome of traditional therapy.

\section{$\underline{\text { Insert Figure } 2 .}$}

\subsection{Current state of affairs}

Also called 2',2'-difluorodeoxycytidine $(\mathrm{dFdC})$ (Figure 1), gemcitabine is a cell cycledependent (S-phase-specific) analogue of deoxycytidine (Figure 2.A). Even if it presents some similarities with other nucleoside analogues (cytosine arabinoside; 
AraC) (Figure 2.B), it differs in many properties and in its own spectrum of activity. It was originally investigated for its antiviral effects but has since been developed as an active agent for cancer therapy. ${ }^{11}$

This molecule (Gemzar ${ }^{\circledR}$ : commercialised by Eli Lilly and Co.) was approved in 1996 by the Food and Drug Administration as first-line treatment for patients with locallyadvanced (non-resectable Stage II or Stage III) or metastatic (Stage IV) pancreatic cancer. ${ }^{1,12}$ Clinical trials comparing the use of $\mathrm{Gemzar}^{\circledR}$ and 5-FU for patients with locally-advanced or metastatic pancreatic cancer who had received no prior chemotherapy showed that patients treated with Gemzar $^{\circledR}$ had significant increases in positive clinical response, survival, and disease progression time compared to 5FU (Figure 3). In this clinical study, Gemzar ${ }^{\circledR}$ was administered intravenously with a $100 \mathrm{mg} / \mathrm{m}^{2}$-dose for 30 minutes for 7 of the first 8 weeks as a first cycle. From the second cycle, gemcitabine was given weekly for 3 weeks in four-week cycles at the same dose. 5-FU was administered intravenously at a $600 \mathrm{mg} / \mathrm{m}^{2}$-dose for 30 minutes. $^{13}$

\section{Insert.Figure 3.}

The FDA approved the use of Gemzar $^{\circledR}$ in 1996 in combination with cisplatin for the first-line treatment of patients with inoperable, locally-advanced (Stage IIIA or IIIB), or metastatic (Stage IV) non-small cell lung cancer. ${ }^{2}$ Two schedules were investigated and the optimum schedule was sought. With the 4-week schedule, Gemzar ${ }^{\oplus}$ was administered intravenously at a $1,000 \mathrm{mg} / \mathrm{m}^{2}$-dose for 30 minutes on Days 1,8 , and 15 of each 28-day cycle. Cisplatin should be administered intravenously at a $100 \mathrm{mg} / \mathrm{m}^{2}$-dose on Day 1 after the infusion of Gemzar $^{\circledR}$. With the 3-week schedule, 
Gemzar $^{\circledR}$ should be administered intravenously at $1,250 \mathrm{mg} / \mathrm{m} 2$ for 30 minutes on Days 1 and 8 of each 21 -day cycle. Cisplatin should be administered intravenously at a $100 \mathrm{mg} / \mathrm{m}^{2}$-dose after the infusion of Gemzar on Day 1 .

In 2004, the FDA approved the use of gemcitabine in combination with paclitaxel for the first-line treatment of patients with metastatic breast cancer, ${ }^{3}$ and in 2006 in combination with carboplatin for the treatment of patients with advanced ovarian cancer. ${ }^{4}$ For breast cancer, a $1,250 \mathrm{mg} / \mathrm{m}^{2}$-dose of Gemzar ${ }^{\circledR}$ (intravenous infusion for 30 minutes) was administered on Days 1 and 8 of a 21-day cycle with paclitaxel (175mg/m²-dose) (intravenous infusion for 3 hours) administered prior to gemcitabine hydrochloride on Day 1 of each cycle. For ovarian cancer, Gemzar® was administered at a $1,000 \mathrm{mg} / \mathrm{m}^{2}$-dose on Days 1 and 8 of a 21 -day cycle with carboplatin (AUC 4) administered on Day 1 of each cycle.

Until 2008, Eli Lilly had the exclusive rights of sale of gemcitabine in the US and Europe, and sales of Gemzar $\AA$ increased constantly with a turnover of $1,720 \$$ billion. Since 2008, sales have steadily declined with the introduction of generic alternatives. Indeed Gemzar® lost effective exclusivity in the U.S in November 2010 and in major European countries (France, Germany, Italy, Spain and the United Kingdom) in March 2009. In 2009 and 2010, sales outside the U.S. decreased by $37 \%$ and $31 \%$, respectively; and in 2010 a decrease of $3 \%$ in the U.S was observed, driven by reduced demand and lower prices as a result of the entry of generic competition. ${ }^{14}$ 


\subsection{Biodistribution}

Gemcitabine has a very short plasma circulation time. The elimination half-life depends upon the infusion time, and the age and the gender of the patient (Table 1). For short infusions, the half-life is from 42 to 94 minutes. For infusions of seventy minutes, the half-life is 4 to 10 hours, and is associated with increased toxicity. At higher doses, major toxicity can be observed, such as: neutropaenia, reversible hepatic transaminase increases, proteinuria, nausea and vomiting, mild flulike syndrome, and mild skin rash. ${ }^{15}$ Gemcitabine is rapidly cleared from the body upon its enzymatic conversion in the blood, liver, kidney and various tumour tissues. ${ }^{16}$

\section{Insert Table 1.}

\subsection{Mechanisms of actions}

Gemcitabine is transported across the plasma membrane by sodium-dependent (concentrative nucleoside transporter hCNTs) and by sodium-independent (equilibrative nucleoside transporter hENTs) mechanisms. ${ }^{5,17}$ Gemcitabine is transported into cells by five nucleoside transporters, two equilibrative nucleoside transporters hENT1 and hENT2 and three concentrative nucleoside transporters hCNT1, hCNT2, and hCNT3. hENTs mediate bidirectional transport of nucleosides across biological membranes down a concentration gradient and are found in most tissues in the body. The hCNT family members are cation-dependent symporters that mediate unidirectional transport of nucleosides into cells. ${ }^{18}$ Kinetic studies have shown that gemcitabine intracellular uptake is preferentially directed by hENT1 and, to a lesser extent, by hCNT1 and hCNT3. ${ }^{19,20}$ Several studies have shown the importance of the presence of the hENT1 transporter for an optimal response to 
gemcitabine. ${ }^{21}$ One study has shown that in patients with pancreatic cancer, those with the highest level of hENT1 mRNA expression had a significant increase in survival time compared with patients expressing low hENT1 levels. ${ }^{22}$

In cells, gemcitabine undergoes a series of phosphorylations, essential to make it active (Figure 4). Firstly it is phosphorylated to a monophosphate compound ( $(\mathrm{fFdCMP})$ by deoxycytidine kinase (dCK). It then undergoes a second modification to become gemcitabine diphosphate ( $\mathrm{dFdCDP}$ ), and finally to gemcitabine triphosphate (dFdCTP), all catalysed by nucleoside monophosphate kinase (UMP / CMP) and diphosphate kinase, respectively. Gemcitabine inactivation is catalysed by cytidine deaminase (CDA) as well as the deamination of gemcitabine monophosphate, which is catalysed by deoxycytidylate deaminase (DCTD). Phosphorylated metabolites of gemcitabine are reduced by cellular $5^{\prime}$-nucleotidase (5'-NT), and dFdCMP is also converted, and inactivated, by DCTD into 2'-deoxy-2',2'-difluorouridine monophosphate (dFdUMP).

\section{$\underline{\text { Insert Figure } 4}$}

The triphosphate form of gemcitabine acts as a competitive substrate of deoxycytidine triphosphate. Its analogy allows it to be incorporated into DNA during replication, thus inhibiting chain elongation of DNA and causing cell death by apoptosis. Once gemcitabine triphosphate is incorporated at the end of the elongated DNA strand, one deoxynucleotide is added, and thereafter the DNA polymerases are unable to proceed. This action, called "masked chain termination", appears to lock the drug into DNA because proof-reading exonucleases are unable to remove 
gemcitabine nucleotide from this penultimate position. ${ }^{23,24}$ The inhibitory action of gemcitabine is enhanced by its non detection in the DNA chain.

Gemcitabine exhibits a unique property called self-potention which enhances its activation. The diphosphate form (dFdCDP) inhibits ribonucleoside diphosphate reductase (RNR), an enzyme of DNA synthesis, which permits the formation of nucleoside triphosphates. This results in a significant decrease in the concentration of cellular deoxycytidine triphosphate (dCTP) and a change in the ratio of dCTP / dFdCTP in favour of dFdCTP. The accumulation of gemcitabine triphosphate and the intra-cellular reduction of dCTP results in the inhibition of dFdCMP inactivation by DCTD, which requires sufficient concentrations of dCTP to be active. ${ }^{25}$

Thymidylate synthase (TS), which plays a key role in the synthesis of thymidine monophosphate, has been studied to investigate the possible inhibition of TS by gemcitabine exposure. The natural substrate of TS, 2'-deoxyuridine monophosphate (dUMP) is converted into 2'-deoxythymidine-monophosphate (dTMP). Thereby analogues of dUMP are potential TS inhibitors, and the deaminated product of gemcitabine dFdUMP resembles dUMP. ${ }^{26}$ Studies with the human ovarian cancer cell line A2780 and the murine colon carcinoma cell line C26-10, have show inhibition of $90 \%$ of TS activity after $24 \mathrm{~h}$ exposure to gemcitabine. ${ }^{27}$ The expression of TS provides an alternative source of substrate for DNA synthesis and positively correlates with gemcitabine resistance and shortened patient survival time. Another study has proved that removing TS protein expression by siRNA induces a high degree of growth inhibition by gemcitabine, indicating the critical relation of TS to the enhancement of the therapeutic effect of gemcitabine. ${ }^{28} \mathrm{~A}$ final, less well known and 
less studied mode of action of gemcitabine is its incorporation into RNA which seems to be concentration-dependent. ${ }^{29}$

\subsection{Resistance}

Many forms of cancer show initial sensitivity to gemcitabine therapy followed by the rapid development of resistance, a feature that essentially characterises this disease. Thus, a better understanding of the origins of gemcitabine resistance is critical to the development of improved combination therapies to replace gemcitabine or to improve gemcitabine targeting. Resistance to antimetabolic drugs such as gemcitabine can be achieved by various genomic alterations. ${ }^{29}$

A major cause of resistance can be attributed to alterations in the transporter. The development of resistance to gemcitabine correlates strongly with a deficiency of hENT1 expression in human breast and pancreatic cancer cells. ${ }^{5,30}$ Many studies have shown that the hENT1 but also hCNT3 expression determination can be used as a prognostic marker to provide prospective evaluations for patients receiving gemcitabine-based adjuvant therapy. ${ }^{6,31,32}$

In L1210 murine leukaemia cells made resistant to ara-C and cross-resistant to gemcitabine, altered action of dCK can be observed, due to genomic recombination. $^{27}$ These results suggest that a partial deletion of the dCK gene observed after selection in the presence of gemcitabine is involved with resistance to this agent both in vitro and in vivo. The expression of dCK has been postulated to be correlative to gemcitabine resistance. ${ }^{33}$ 
Another factor in gemcitabine resistance is the over-expression of ribonucleotide reductase $(\mathrm{RR}){ }^{34} \mathrm{RR}$ is a dimeric enzyme composed of regulatory subunit M1 (RRM1) and catalytic subunit M2 (RRM2). Ribonucleotide reductase is mainly responsible for the conversion of ribonucleosides to deoxyribonucleoside triphosphates (dNTPs), which are essential for DNA polymerisation and repair. RRM1 over-expression through transfection of a lung cancer cell line likewise resulted in gemcitabine resistance. Reduction of RRM1 expression through RNA interference abrogated the induced gemcitabine resistance. ${ }^{35}$ Ribonucleotide reductase enzymatic activity is modulated by levels of its M2 subunit. An over-expression of RRM2 is associated with resistance to gemcitabine and down regulation of RRM2 by siRNA enhanced gemcitabine cytotoxicity, both in vitro and in vivo in pancreatic adenocarcinoma. ${ }^{7}$ Gemcitabine monophosphate and triphosphate are reduced respectively by dCMP deaminase and by $5^{\prime}$-nucleotidase ( $\left.5^{\prime}-\mathrm{NT}\right)$, and gemcitabine itself is inactivated by cytidine deaminase (CDA). High levels of these catabolic enzymes are associated with resistance to the drug. ${ }^{36}$

Apoptosis forms the principal cause of cell death in response to cytotoxic drug treatment. A variety of anticancer drugs have been shown to produce extensive apoptosis in sensitive malignant cells, but it has been suggested that the inability of some cells to undergo apoptosis is similar to the mechanism of gemcitabine resistance. The expression of $\mathrm{p} 53$, which plays an important role in apoptosis pathways, induces cell cycle arrest and, in the higher concentration ranges, p53 induces apoptosis. On the other hand, human lung cancer expressing the mutation of the p53 gene does not undergo apoptosis after gemcitabine treatment. ${ }^{37}$ The 
aberrant expression of genes associated with cellular survival and apoptosis are implicated in gemcitabine resistance.

New resistance mechanisms to gemcitabine implicate the stress-response protein $\mathrm{Hu}$ antigen $\mathrm{R}$ (HuR) which is an RNA-binding protein that post-transcriptionally regulates gene expression. A recent study has shown a relation between HuR and gemcitabine resistance. After treatment of a MiaPaCa-2 cell line with gemcitabine, increased HuR cytoplasmic levels and a reaction to the drug were observed. Since the dCK $3^{\prime} U T R$ region contains 8 putative hits of an HuR recognition motif, HuR associated with dCK mRNA was tested and a bond of HuR with the dCK 3'UTR was obtained. A correlation between the level of HuR and the dCK protein levels, but not the dCKA mRNA, was observed. Regulation of dCK protein concentration by HuR and the prediction of gemcitabine response by cytoplasmic HuR levels was suspected. ${ }^{38}$ Nevertheless a recent study has shown that HuR binds to VEGF mRNA, implying regulation of VEGF expression in pancreatic ductual andenocarcinoma after gemcitabine exposure. ${ }^{39}$ Taken together, these data suggest that the genes encoding proteins involved in the transport and metabolism of gemcitabine and in the metabolism of targets can be potential candidates to predict sensitivity to gemcitabine. Quantitative analyses of these genes can be a potent tool to perform individualised chemotherapy.

Gemcitabine is a polar drug with low membrane permeability and which is extensively degraded by cytidine deaminase into an inactive metabolite in the liver. Moreover, the increasing amount of resistance also reduces its cytotoxicity. Thus, a frequent administration schedule at high drug doses is required, and this leads to serious side 
effects such as: myelosuppression, high levels of hepatoxicity, renal toxicity, thrombocytopaenia and anaemia. ${ }^{40}$ To date, various innovative approaches have been developed to overcome these disadvantages. We will focus on chemical modifications at the $4-(N)$ - and 5 ' position of gemcitabine.

\section{4 - $(N)$ - MODIFICATION OF GEMCITABINE}

\subsection{PEG-gemcitabine}

For 40 years, several antitumour agents, either proteins, peptides or low molecularweight drugs, have been considered for PEG conjugation. PEGylation can give a number of relevant advantages such as considerable in vivo half-life prolongation, a reduction or removal of immunogenicity, and a reduction of aggregation. ${ }^{41}$

The technique has become the leading approach for overcoming most of the aforementioned biological limits, and the number of PEGylated products on the market and in clinical trials is increasing constantly. ${ }^{42,43}$ The PEGylation process presents many advantages: (i) PEG is a polymer with high solubility in water and excellent biocompatibility (it is FDA-approved for human administration by mouth, injection or dermal application ${ }^{44}$ ), (ii) plasma half-life of pegylated product is increased, (iii) it provides enzymes protection, (iv) it accumulates in tumour zones according to the "enhanced permeability and retention" effect (EPR). ${ }^{45,46}$ However a number of drugs encapsulated or solubilizing with pegylated agents can activate the complement system, the nonspecific, humoral arm of antimicrobial immune defense. Complement activation has been recently proposed as a major underlying or contributing cause of infusion reactions, referred to as complement-activation related pseudoallergy (CARPA). CARPA may be a major underlying cause, or contributing 
factor to the hypersensitivity reactions (HSRs) caused by many successful drugs, such as Taxol ${ }^{\circledR}$ and Doxil ${ }^{\circledR} 47$

Clinical trials of several derivatives of PEG coupled to anticancer drugs are already under way or have been completed. ${ }^{43}$ Pegamotecan (Enzon Pharmaceuticals, Inc.) is a prodrug obtained by coupling two molecules of camptothecin to a PEG of $40 \mathrm{kDa}$. An amphiphilic polymer-docetaxel conjugate was prepared by attaching PEG to docetaxel through an ester linkage. The PEG-docetaxel was used to form nano-sized micelles for the solubilisation of free docetaxel. A 1.8-fold higher area under the curve (AUC) for docetaxel equivalent plasma concentration vs. time was obtained, in comparison with free docetaxel. The maximum tolerated dose of PEG-docetaxel was also 2.5 -fold higher than that for free docetaxel in healthy mice. ${ }^{48}$ Studies with paclitaxel were also conducted: PEG (5000 Da) was bound to the 2' position of paclitaxel through a spacer succinyl group and this prodrug increased the half-life of PEG-paclitaxel. ${ }^{49}$ Other studies have shown the importance of conjugation with PEGs with a molecular weight $\geq 30 \mathrm{kDa}$, in order to prevent rapid elimination by the kidneys. ${ }^{43}$ Because of encouraging results from studies with other anticancer agents and because the anti-cancer effects of gemcitabine is limited by its short half-life, its rapid metabolisation and its low tumour uptake, the addition of PEG on gemcitabine has been tested by several research teams. In a recent paper, a synthesis of a PEGgemcitabine, by conjugating the amino groups at 4-(N)-position of gemcitabine to $\mathrm{N}$ hydroxysuccinimide derivative of PEG, has been carried out (Figure 2.C).$^{50}$

Confocal analysis showed PEG-gemcitabine colocalisation in lysosome and endosome after $24 \mathrm{~h}$ incubation and an enhanced retention in cancer cells after 3 days of incubation in comparison to native gemcitabine. It is known that the cellular 
uptake of PEG-drugs occurs through endocytosis and they are retained in transport vesicles which traffic along the endo-lysosomal scaffold which are acidic in nature. $^{51,52}$ The endo-lysosomal transport vesicles allow cleavage of the amides bounds between PEG and gemcitabine, thanks the acidic nature of these vesicles, and thereby allow its prolonged release. Pharmacokinetic studies have shown consistently higher bioavailability (21 times) of PEG-gemcitabine over native gemcitabine, after $1 \mathrm{~h}$ of intravenous administration in mice (Figure 5). In MiaPaCA 2 and PANC-1 PEG-gemcitabine was more effective in all cases in comparison with native gemcitabine.

To improve the effect of PEG-gemcitabine, folic acid has recently been conjugated to PEG-gemcitabine (Figure 2.E) to evaluate their active targeting and cytotoxic superiority compared the non-targeted PEG-gemcitabine. ${ }^{53}$ The drug linkage involved the 4-(N)-amino group of gemcitabine and the $\mathrm{COOH}$ of PEG, while folic acid was linked through its carboxylic function to PEG amino group. Folic acid was chosen as the targeting agent because its receptor is over-expressed in several types of cancers (lung, breast, kidney and ovarian), ${ }^{54-56}$ while in normal human tissues its receptors maybe have limited distribution. Effective targeting with folate has been proven by using folate on the surface of many nanocarriers such as gold nanoparticles, liposomes or magnetic nanoparticles for the detection of cancer cells and the release of anticancer drugs. ${ }^{57-59}$

All conjugates were able to release the drug in a $\mathrm{pH}$-dependent manner with no role played by enzymes. The presence of a plasma enzyme does not accelerate the conversion of different compounds in dFdU which confirms previous studies showing 
that the protection of the amino group of gemcitabine prevents this. ${ }^{60}$ Polymer conjugation of gemcitabine increases drug plasma half-life, which is dependent on the polymer's molecular weight, by reducing its kidney clearance. An increase of $t_{1 / 2}$ $\alpha, t_{1 / 2} \beta$ and the area under the curve was obtained. The results of cytotoxicity tests showed no improvement of PEG-gemcitabine (with or without folic acid), compared to native gemcitabine, on tumour cell lines which did not over-express the folate receptor. Folic acid derivatives are less toxic than PEG derivatives. This is explained by a slower entry into the cell by endocytosis and a cytotoxic activity only after the release of gemcitabine. Moreover, the polymer derivatives targeting folate receptors need a receptor-mediated endocytosis mechanism for cell penetration in cells that do not over-express the folate receptor. Folate-targeted poly(ethylene glycol) (PEG)coated nanoparticles are found to bind to folate receptors triggering for caveolaeassisted endocytosis, followed by the formation of intracellular vesicles which can be visualised by confocal microscopy. ${ }^{61}$ In contrast, in KB-3-1 cells which over-express folate receptors, derivatives with folate are certainly less cytotoxic than native gemcitabine but are more cytotoxic than gemcitabine only coupled to PEG. ${ }^{53}$

PEGylation is currently considered to be one of the most successful techniques to prolong the residence time of drugs in the bloodstream. In a few cases, polymer conjugation has also shown that it can confer targeting properties to the disease site, such as tumour masses, by passive diffusion (EPR effect). ${ }^{62}$ Different studies have proven the interesting use of PEG-like drug carriers. They permit an increase of drug plasma half-life, prevent the degradation action of cytidine-deaminase enzyme, increase the availability after intravenous injection, and in certain cases increase the 
cytotoxicity against cancer cells. The easy addition of an agent that specifically targets cancer cells in the case of folic acid is also a benefit of the use of PEGylation.

$\underline{\text { Insert Figure } 5 .}$

\section{$2.2 \quad$ LY2334737}

Gemcitabine has poor oral bioavailability due to an extensive first pass metabolism by cytidine deaminase. To circumvent this rapid deamination into 2',2'difluorodeoxyuridine ( $\mathrm{dFdU}$ ), a gemcitabine prodrug has been developed, LY2334737 (Figure 2.D). LY2334737 is an oral gemcitabine prodrug in which gemcitabine is linked to valproic acid via an amide bond at 4-(N)-position, enabling it to bypass hydrolysis in enterocytes and portal circulation, thereby avoiding the extensive first pass metabolism that occurs with unmodified gemcitabine. Circulating levels of LY2334737 are detectable several hours after oral administration. In addition, a gradual release of gemcitabine following cleavage of the amide bond should enhance efficacy, since more cancer cells should be exposed to a continuous effective cytotoxic level of gemcitabine. The stability of the prodrug was tested on a $\mathrm{pH}$ range from 1 to 8 to check the possibility of delivering an intact prodrug into systemic circulation after passing through the gastrointestinal tract after oral administration. LY2334737 is $\mathrm{pH}$-dependent with about $21 \%$ degradation at $\mathrm{pH} 1$ and no degradation between $\mathrm{pH} 6$ to 8 , after $4 \mathrm{~h}$ of incubation at $40^{\circ} \mathrm{C}^{63}$ In vitro hydrolysis profiles showed a slow hydrolysis in the liver (subcellular fractions S9 that contain drug-metabolising enzymes) and in crude homogenates of small intestinal epithelial cells with 27 and $11 \mathrm{pmol} / \mathrm{mg}$.min, respectively. In vivo antitumour activity with mice bearing HCT-116 human colon tumour xenografts, indicated the same efficacy of 
LY2334737 after an oral administration at a $7.55 \mathrm{mg} / \mathrm{kg}$-dose for 14 days vs 4 doses of an intraperitoneal administration of gemcitabine at a $160 \mathrm{mg} / \mathrm{kg}$-dose. Phase I trials of LY2334737 either as monotherapy or in combination with other agents are currently under way to determine the maximum tolerated dose and dose limiting toxicities of daily administration. ${ }^{64}$

\subsection{Squalenoylation}

Squalene is a triterpene that is an intermediate in the cholesterol biosynthesis pathway. Squalene is a structurally-unique triterpene compound that is one of the main components (about 13\%) of skin surface lipids. It was so called due to its first historical isolation from shark liver oil, where it is contained in large quantities, and is considered its richest source.$^{65}$ In humans, about 60 percent of dietary squalene is absorbed and is distributed ubiquitously in human tissues in small amount. ${ }^{66}$ Recent in vitro and in vivo model experiments suggest a tumour-inhibiting role for squalene. ${ }^{67}$

Pr. Couvreur's team developed the concept of squalenoylation involving the chemical linkage of squalene with various nucleoside analogues which allowed the formation of novel colloidal nano-assemblies of $100-300 \mathrm{~nm}$ with a narrow size distribution, after dispersion in an aqueous environment. ${ }^{68}$ They were interested in the pharmacological activity of gemcitabine covalently coupled at 4-(N)-position with 1,1', 2-tris-nor-squalenoic acid to obtain Sq-gemcitabine (4-(N)-Tris-nor-squalenoylgemcitabine, SQdFdC) (Figure 2.F). A study by X-ray diffraction (SAXS) combined with molecular modelling identified the supramolecular organisation of these nanoassemblies, which form an inverse, hexagonal phase, in which the central aqueous core consisting of water and gemcitabine molecules was surrounded by the squalene 
moieties. ${ }^{69}$ They investigated the anticancer activity of Sq-gemcitabine in vitro on resistant murine and human leukaemia cells (L1210 10K and CEM/ARAC8C, respectively). The L1210 10K cells were characterised by a lower expression of cytoplasmic dCK and CEM/ARAC8C by a deficiency in hENT1 transporters, ${ }^{70,71}$ these two ways representing two major resistance factors to gemcitabine. After $72 \mathrm{~h}$ of incubation with different concentrations, Sq-gemcitabine demonstrated 3.26 and 3.22-fold higher cytotoxicity compared to gemcitabine with L1210 $10 \mathrm{~K}$ and CEM/ARAC8C, respectively. ${ }^{72}$ After intravenous injection of Sq-gemcitabine in aggressive leukaemia-bearing mice, an increase in survival time compared to gemcitabine was obtained. This significant increase was attributed to the high degree of localisation of Sq-gemcitabine in the liver and spleen which are the major metastatic organs. Sq-gemcitabine was found to be more efficient than gemcitabine, suggesting the considerable potential of this treatment for leukaemia.

Studies on human pancreatic adenocarcinoma models were also performed. In vitro, Sq-gemcitabine showed higher antiproliferative and cytotoxic effects compared to native gemcitabine, on chemoresistant tumour cells (Panc-1) and sensitive cell lines (Capan1 and BxPc3), which were associated with significant DNA synthesis inhibition, S-phase arrest, and higher induction of apoptosis (caspase 3 activation). In vivo experiments were performed with subcutaneous tumour models (Panc1 and Capan1) and orthotopic tumours (Panc1). Sq-gemcitabine treatment exerted significant inhibition of tumour growth in all types of tumour models compared to gemcitabine, and avoided the formation of metastatis spreading in the peritoneum, and prolonged the survival time of mice with orthotopic pancreatic tumours (Figure $6)^{73}$ 
The impact of the encapsulation of Sq-gemcitabine in liposomes on a model of subcutaneous leukaemia (L1210wt) was also studied. PEGylated liposomeS were employed to modify the drug pharmacokinetics and biodistribution to enhance the anticancer activity (accumulation in tumours due to their ability to extravasate into these tissues by the EPR effect) and to decrease the capture by macrophages in organs of the reticuloendothelial system. ${ }^{74}$ PEGylated liposomal formulations exhibited a hydrodynamic diameter of $133 \pm 24 \mathrm{~nm}$ with a polydispersity index of 0.035 and were stable for 2 weeks. A similar in vivo anticancer activity of Sqgemcitabine in pegylated-liposomes compared to native gemcitabine was demonstrated, with a drug dosage 5-fold lower than free gemcitabine on a subcutaneous grafted L1210wt leukaemia model. They explained this by the protection of gemcitabine from deamination in the blood.

A novel innovative nanoparticle system is currently being developed using Sqgemcitabine: nanocarriers are able to target the tumour due to the presence of magnetite nanocrystals formed in the self-assembly of the squalenoyl gemcitabine bioconjugate. ${ }^{75}$ These particles were thought to be compatible with parenteral administration. After intravenous injection, in L1210 subcutaneous tumour model mice, the new assembly of magnetite-Sq-gemcitabine was guided to the tumour by a magnet placed at the tumour location. Considerable inhibition of tumour growth and an accumulation of the product in the tumour periphery was observed using $T_{2}-$ weighted imaging in magnetic resonance imaging. 
While the mechanism of entry and metabolisation of gemcitabine into cells is known, the cellular uptake mechanism of Sq-gemcitabine, its subcellular localisation, and its metabolisation pathway have only been studied recently. An in vitro passive entry in cancer cells (MCF-7: human breast adenocarcinoma) and a preferential accumulation in endoplasmic reticulum, thanks the high lipophilic level of squalene, were observed. ${ }^{76}$ This passive input may explain the efficacy of Sq-gemctiabine on cell lines deficient in active transporters. ${ }^{72}$

In addition to storage, a gradual cleavage of Sq-gemcitabine in native and active form also explains his efficiency. Cathepsin B, a lysosomal enzyme often overexpressed in cancer cells, ${ }^{72}$ was shown to be responsible for the amidic-linkage degradation of this nanosystem inside the cells. The role of cathepsin $B$ and $D$ in the cleavage of the Sq-gemcitabine has been shown, increasing half-life in blood from $1.5 \mathrm{~h}$ to $8 \mathrm{~h}$, for native gemcitabine and Sq-gemcitabine, respectively, ${ }^{79}$ thus increasing its anticancer activity through its longer presence in the blood. Two important elements have contributed to the efficiency of this new drug: (i) the storage of gemcitabine in the endoplasmic reticulum have allowed it to be protected from deamination by the presence of squalene and (ii) the progressive cleavage in its native form allowed the metabolisation of the cancer compound. The concept of squalenoylation has also been applied to other nucleoside analogues. ${ }^{69}$ Whatever the squalene binding position (heterocycle or sugar), these molecules also selforganise in water as nanoparticles of $100-200 \mathrm{~nm}$. A variety of novel squalene-based prodrugs of the anticancer compound paclitaxel have been synthesised and have produced nanoparticles in water. ${ }^{80}$ Preliminary results show a notable cytotoxicity on a murine lung carcinoma cell line (M109). 


\section{Insert Figure 6.}

\subsection{Lipophilic prodrugs}

An approach to improve the stability and cytotoxic activity of gemcitabine is to protect the amine group by forming a prodrug and by incorporating it into particles like the Sq-gemcitabine loading in liposomes. Many native gemcitabine-loaded particles have already been studied. Liposomes, PLGA-, polycyanoacrylate-, chitosan- or albulminnanoparticles, and carbon nanotubes can be cited. ${ }^{81-85}$ In addition, the coencapsulation of gemcitabine with other anticancer drugs inside a particle to obtain a synergistic effect has been achieved. ${ }^{86}$ Nanoparticles have the advantages of: high stability, high carrier capacity, incorporation of hydrophobic and hydrophilic compounds, and being injectable through various routes of administration. Encapsulation improves the cytotoxic activity of the drug with protection against metabolic inactivation. ${ }^{87}$ In addition, extended circulation in the blood by the addition of PEG on the surface of nanocarriers and an active targeting by grafting peptides or antibodies to the shell of nanocarriers result in sustained exposure to tumour cells and enhanced efficacy. ${ }^{88,89}$

In 1998, Eli Lilly patented the synthesis of lipophilic gemcitabine. To protect against the deamination of gemcitabine, it was proposed to covalently link the amino group in position 4 with saturated and mono-unsaturated, long-chain C18 and C20. The results showed better cytotoxicity of lipophilic derivatives in comparison to native gemcitabine. A few years later, the synthesis of a series of $4-(N)$-acyl derivative prodrugs of gemcitabine was carried out, firstly to prevent diffusion through liposome bilayers, and later to be encapsulated into other particles. ${ }^{90}$ Tokunaga $Y$ et al. 
improved metabolic stability with the synthesis of a series of prodrugs of gemcitabine, increasing lipophilicity, by linking the 4-(N)-position with valeroyl, heptanoyl, lauroyl and stearoyl derivatives (Figure 2.G) and encapsulated them into liposomes. ${ }^{91}$ Liposomal formulations containing these lipophilic prodrugs of gemcitabine increased the drug entrapment efficacy with respect to conventional liposomes but their encapsulation efficiency (EE) closely depended on the length of the 4-(N)-acyl chain, the phospholipids and the presence of cholesterol. Better results were obtained by incorporating 4-( $(M)$-lauroyl-gemcitabine (GemC12) and 4-( $M$-stearoyl-gemcitabine (GemC18) in liposomes composed by DSPC/DSPG 9:1 (EE of $94.4 \pm 7.9 \%$ and $97.7 \pm 2.3 \%$, respectively). Native gemcitabine is well known to rapidly convert to inactive metabolite by cytidine deaminase which is widely distributed in plasma but C12 and C18 derivatives are both stable in plasma. After $24 \mathrm{~h}$, more than $60 \%$ of unmodified prodrugs were still present, with GemC12 and GemC18 derivatives, so that after $8 \mathrm{~h}$ of incubation in plasma, only $40 \%$ of unmodified drug was present with native gemcitabine. $\mathrm{pH}$ stability was obtained in the $\mathrm{pH}$ range 4-9, which confirms the stable amide linkage. In vitro studies have shown that cytotoxicity of free or encapsulated GemC12 and GemC18 derivatives were 2- and 7-fold (in KB and HT29 cells line, respectively) greater than that of native gemcitabine. Encapsulation of the $\mathrm{C} 18$ derivatives into liposomes produced an increase of plasma availability: the AUC was 50 times higher than for native gemcitabine, resulting in the increased accumulation in tumour cells and a high level of antitumoural efficacy in mice grafted with HT-29 and KB 396p cells. ${ }^{92}$

The feasibility of adding GemC18 into other particles to overcome gemcitabine resistance in cancer cells has been evaluated recently in different studies. ${ }^{93-95}$ GemC18 was incorporated into lipid nanoparticles (NPs) engineered from 
lecithin/glycerol monostearate-in-water emulsions. ${ }^{93}$ In vitro studies were performed with a deficient hENT1 cell line (CCRF-CEM-AraC-8C) ${ }^{94}$ Native gemcitabine was not able to enter the cells efficiently, but the GemC18-NPs were able to efficiently deliver the stearoyl gemcitabine into cells by endocytosis and caused apoptosis via caspase3 activation. Thus in the hENT1 deficient cell line, the GemC18-NPs were 15-fold more cytotoxic than gemcitabine. A second resistant cancer cell line, TC-1-GR, that over-expressed ribonucleotide reductase subunit M1 (RRM1), was tested in vitro and in vivo. In both cases treatment with GemC18-NPs efficiently inhibited the growth of cancer cells. ${ }^{96}$

PEGylated nanoparticles were also formulated and evaluated in vitro and in vivo with a pancreatic cancer cell line, BxPc-3. ${ }^{93}$ In vitro, GemC18-NPs and PEG- GemC18NPs were less cytotoxic than native gemcitabine and the addition of PEG did not show any difference in toxicity. However in vivo, GemC18-NPs and PEG- GemC18NPs were more efficient than gemcitabine in controlling the growth of tumours. The in vitro decrease in cytotoxicity was explained by a longer uptake into the cell of the particles (by endocytosis), then a gradual release and finally hydrolysis of the GemC18. This explains a lower cytotoxicity level compared to free gemcitabine with an equivalent incubation time. In vivo, PEG-GemC18-NPs significantly increased the accumulation of nanoparticles in the tumours (6.3-fold) and blood circulation (5.3-fold after 24h) (Figure 7.A and B). The addition of PEG also caused a decrease in the accumulation of nanoparticles in the reticulo endothelial system such as the liver and spleen (Figure 7.C). Despite an increase in circulation time and tumour accumulation, the PEG-GemC18-NPs did not significantly show different antitumour activities with GemC18-NPs. 
In a recent study, the active targeting of nanoparticles has been tested to increase the antitumour effect of the particles. For this, the epithelial growth factor (EGF) was conjugated to the particle surface to target the epidermal growth factor receptor (EGFR). ${ }^{95}$ Elevated levels of the epidermal growth factor receptor (EGFR), a growthfactor-receptor tyrosine kinase, was identified as a common component of multiple cancer types and appeared to promote solid tumour growth. The EGFR was found to act as a strong prognostic indicator in head and neck, ovarian, cervical, bladder and oesophageal cancer. ${ }^{97}$ The epidermal growth factor receptor (EGFR) is overexpressed in $80 \%$ of non-small cell lung cancer (NSCLC), ${ }^{98} 80-100 \%$ of human head and neck cancer cells, $14-91 \%$ of human breast cancer cells, and $30-50 \%$ of human pancreatic cancer cells. ${ }^{95}$ Epidermal growth factor receptor (EGFR) is an important anti-cancer therapy target that is applicable to many cancer types. ${ }^{99}$ Anti-EGFR antibodies and EGF have been conjugated onto liposomes, lipid nanoparticles, chitosan particles and magnetic particles to target cancer cells over-expressing EGFR and the delivery of anticancer drugs or siRNA. In vitro uptake and cytotoxicity of EGF-GemC18-NPs realised with different human breast adenocarcinoma cell lines showed a correlation between EGFR density on the cell surface and cell uptake and toxicity. ${ }^{86,98,100,101}$ In cell culture, EGF-GemC18-NPs uptake by tumour cells was correlated to the EGFR density, whereas the uptake of untargeted GemC18-NPs exhibited no difference among those same cell lines. The relative cytotoxicity of the EGF-conjugated GemC18-NPs to tumour cells in cell culture was correlated to EGFR expression as well, with more internalised EGF-GemC18-NPs and higher expected cytotoxicity. In vivo efficacy, with mice bearing MDA-MB-468 tumours (human breast adenocarcinoma cell lines over-express EGFR with $1 \times 10^{6}$ receptors per cell), confirmed the effectiveness of EGF-GemC18-NPs. Mice treated with EGF-GemC18- 
NPs had a longer life and significantly slower tumour growth than mice treated with untargeted GemC18-NPs, due to the EGF's ability to increase the accumulation of EGF-GemC18-NPs in the tumours.

The increase of anticancer activity observed with these lipophilic derivatives compared with native gemcitabine was obtained at the expense of their solubility in aqueous media. Indeed, with their highly lipophilic properties, these compounds proved difficult to reconcile with intravenous administration and hence encapsulation is necessary. The modification of lipophilic behaviour and encapsulation could be considered a good and versatile antitumoral approach against several tumours which become less sensitive to the native drug.

Insert Figure 7.

\section{5' MODIFICATIONS OF GEMCITABINE}

\subsection{CP-4126}

In order to enhance cellular uptake, to prolong cell retention, and increase the halflife of gemcitabine with a less hydrophilic drug, derivatives containing a fatty acid side chain have been developed. ${ }^{102,103}$ Gemcitabine containing a fatty acid chain at the 5' position of the nucleoside (CP-4126) has been developed (Figure 2.H). The fatty acid was esterified to the $5^{\prime}$ position on a sugar moiety. CP-4126 contains a fatty acid with a chain length of 18 carbon atoms and one trans-double bond (elaidic acid) in position 9. Due to its different molecular design, CP-4126 is absorbed by cancer cells independent of hENT1 levels, which improves its efficacy in tumours with low or no hENT1 expression. Altered membrane transport is also a mechanism of 1- $\beta$-D- 
arabinofuranosylcytosine (Ara-C) resistance. Similarly, in order to facilitate ara-C uptake and prolong retention in the cell, lipophilic prodrugs have been synthesised and in particular CP-4055 with the same modification as CP-4126. ${ }^{10} \mathrm{CP}-4055$ showed a higher activity compared to Ara-C in several human solid tumourS and leukaemia xenografts. In vitro studies with inhibitors of nucleoside carrier-dependent transport, nitrobenzylmercaptopurine riboside and dipyridamol, strongly reduce the cellular sensitivity to Ara-C, but not to CP-4055, indicating that CP-4055 uses an alternative/additional mechanism for internalisation into the cell compared with AraC. ${ }^{104}$ CP-4055 or ELACYT ${ }^{\circledR}$ is currently being tested in several clinical studies: phase II in Acute Myeloid Leukemia (AML), phase I in haematology in combination with idarubicin (Idamycin ${ }^{\circledR}$ ), phase II in colorectal cancer, phase II in malignant melanoma in combination with sorafenib (Nexavar $\left.{ }^{\circledR}\right)$ and phase II in ovarian cancer. ${ }^{105-107}$

In vitro tests have shown that IC50 of gemcitabine increased up to 200 -fold in deficient nucleoside transport cell lines, but there was no difference with CP-4126, suggesting a nucleoside transporter-independent transport in the cell of the fatty acid derivative. ${ }^{108}$ Inside the cell, CP-4126 was localised in the membrane and the cytosolic fraction, leading to long retention after removal of the cell culture medium. This accumulation caused a slower and prolonged release of the gemcitabine from the lipophilic analogue. CP-4126 needs to be converted into gemcitabine by nonidentified esterases, releasing the fatty acid, in order to be phosphorylated. ${ }^{109} \mathrm{CP}$ 4126 is active in cells with deficient nucleoside membrane transport. ${ }^{110}$ On the other hand, activity of native gemcitabine and CP-4126 was comparable in the cell lines without resistance, while in dCK-deficient cells both compounds were inactive. CP4126 is, like native gemcitabine, dependent upon activation by dCK. In vivo studies 
have also shown highly effective action of gemcitabine and CP-4126 in sarcoma, lung, prostate, pancreatic and breast cancer. In contrast to native gemcitabine which was highly toxic via the oral route, CP- 4126 was administered orally with various schedules and an efficient antitumour activity (Figure 8). ${ }^{111}$ CP-4126 was also evaluated for a potential synergy with several clinically-active cytotoxic drugs such as docetaxel, oxaliplatin and pemetrexed. ${ }^{112}$ In vitro preliminary results have shown a synergistic effect in the lung cancer cell line (A549) and the colon cancer cell line (WiDR) with the combination of CP-4126 and oxaliplatin. Furthermore, the combination of docetaxel with CP-4126 induced an accumulation in the G2/M phase in the A549 cell line, but a G0/G1 phase accumulation in the WiDR cell line. Pemetrexed with CP-4126 induced in the A549 cell line an increase of cells in the G0/G1 phase and the S phase.

CP-4126 is currently in a phase II clinical trials in solid tumour patients. ${ }^{109}$ This trial will investigate the use of CP-4126 as a second-line treatment for advanced, metastatic pancreatic cancer in patients refractory to first line gemcitabine treatment, where the resistance mechanism is likely to be due to impaired drug entry into tumour cells. The trial is progressing in Europe, the US, South America and Australia, and results are anticipated for the end of 2012.

\section{$\underline{\text { Insert Figure } 8 .}$}

\subsection{NEO6002}

To enhance the uptake and efficacy by a prolonged release of gemcitabine in cancer cells, NeoPharm has synthesised a novel gemcitabine-cardiolipin conjugate. ${ }^{113}$ This 
approach was to conjugate the ether analogue of synthetic cardiolipin with gemcitabine via a succinate linker. Cardiolipin $(C L)$ is a major membrane phospholipid specifically localised in mitochondria. At the cellular level, CL has been shown to have a role in mitochondrial energy production, mitochondrial membrane dynamics, and the triggering of apoptosis. ${ }^{114}$ The conjugate is called NEO6002 (Figure 2.I).

In vitro studies showed that NEO6002 can improve the efficacy and potentially overcome NT-deficient (nucleoside transporters) gemcitabine-resistant tumours, indicating a different internalisation route of NEO6002. ${ }^{115}$ NeoPharm's studies on NEO6002 showed evidence of cytotoxicity against various cancer cell lines, including: A549 (human lung); BxPC-3 (human pancreas); MX-1 (human breast); HT-29 (human colon) and P388 (murine leukaemia). ${ }^{116}$ Mice bearing or not BxPC-3 tumour xenografts were treated with NEO6002 or Gemzar ${ }^{\circledR}$ and the toxicities for each were evaluated by the mortality, body weight loss, peripheral blood cell counts, and plasma levels of the liver enzymes at the end of the study. Mice treated with Gemzar $^{\circledR}$ for six daily $27 \mu \mathrm{mol} / \mathrm{kg}$-doses were all moribund whereas no mouse treated with NEO6002 died. This suggested that NEO6002 was less toxic at equimolar dosage when compared with Gemzar ${ }^{\circledR}$. In mice bearing BxPC-3 tumours, at a dose of $18 \mu \mathrm{mol} / \mathrm{kg}$, NEO6002 inhibited the growth of BxPC-3 xenografts by $52 \%$, while only $32 \%$ of tumour inhibition was achieved with Gemzar $^{\circledR}$.

\subsection{Phosphoramidate Gemcitabine}

The obligatory phosphorylation is often the rate-limiting step in the activation process of many anti-cancer drugs and is therefore still one of the limiting factors for the 
therapeutic use of nucleoside analogues. Hence, different strategies to improve the antitumour efficacy of nucleoside analogues are being investigated.

The use of modified nucleotide prodrugs incorporating a phosphate function protecting group, has led to the selective release of the mono-phosphorylated nucleoside analogue. ${ }^{117}$ This is the case of AraC grafted with an S-pivaloyl-2thioethyl (tBuSATA). ${ }^{118}$ This prodrug has been found to be more efficient than native Ara-C against L1210 10K cells, being totally dCK-deficient. This modification was tested on gemcitabine to get (i) resistance to chemical degradation, (ii) passive diffusion across a cell membrane and (iii) release of the mono-phosphorylated metabolite, independent of kinase expression. These prodrugs are designed to undergo intracellular activation to generate an unstable phosphoramidate intermediate anion, followed by a spontaneous cyclisation and $\mathrm{P}-\mathrm{N}$ bond cleavage by water to liberate the nucleoside monophosphate. ${ }^{119}$ In a patent from 2009, Perigaud et al. explained the synthesis of four derivatives of gemcitabine, $\mathrm{N}-(\mathrm{n}$ butylamino)-O-(S-pivaloyl-2-thioethyl)-O-5' gemcitabine phosphoramidate diester (Gem-1), N-(isopropylamino)-O-(S-pivaloyl-2-thioethyl)-O-5'-gemcitabine phosphoramidate diester (Gem-2), N-(benzylamino)-O-(S-pivaloyl-2-thioethyl)-O-5'gemcitabine phosphoramidate diester (Gem-3), and $\mathrm{N}$-(benzylamino)-O-(S-(2,2dimethyl-3-hydroxypropionyl)-2-thioethyl)-O-5'-gemcitabine phosphoramidate diester (Gem-4) (Figure 2.J-M). A better cytotoxicity level was obtained in preliminary in vitro tests with Gem-1, Gem-2 and Gem-3 compared to the native gemcitabine in L1210 $10 \mathrm{~K}$ cell line $(23.7 \pm 1.2 \mu \mathrm{M}, 18.3 \pm 1.5 \mu \mathrm{M}, 9.7 \pm 9.0 \mu \mathrm{M}, 36.7 \pm 11.6 \mu \mathrm{M}$ respectively). ${ }^{120}$ 
Another approach to deliver nucleoside 5'-monophosphate intracellularly was developed by using other phosphoramidate conjugations. Many phosphoramidate prodrugs have been synthesised with an increase of biological activity in various therapeutic domains like fluoro-2'-deoxyuridine. The cytostatic activity of NUC-3073, a phosphoramidate prodrug of 5-fluoro-2'-deoxyuridine, has been found to be independent from activation by thymidine kinase and non-sensitive to degradation by phosphorolytic enzymes. ${ }^{121}$ Recently INX-08189 has entered human clinical trials. INX-08189 is a phosphoramidate motif and a 6-O-methoxy based-prodrug moiety which are combined to generate lipophilic prodrugs of the guanine monophosphate nucleoside. ${ }^{122}$ The in vitro and in vivo data indicated that INX-08189 was a highly potent inhibitor of the hepatitis $\mathrm{C}$ virus with a high barrier for resistance and good oral pharmacokinetic properties. ${ }^{123}$ This approach was extended to Ara-C and in vitro studies indicated that the phosphoramidate Ara-C was significantly more potent than native Ara-C against transport- and kinase-deficient CEM leukaemia cell lines. ${ }^{124}$ Finally, this approach was used with 2'- $\beta$-D-Arabinouridine (AraU), the uridine analogue of the anticancer agent AraC. Unfortunately, neither the parent compound (AraU) nor any phosphoramidate drugs showed antiviral activity, or potent inhibitory activity against any of the cancer cell lines. ${ }^{125}$ The phophoramidate prodrug approach was extented to gemcitabine to form 5'-(2'-deoxy-2',2'-difluorocytidyl) 5-nitrofurfuryl $\mathrm{N}$-methyl- $\mathrm{N}$-(4-chlorobutyl) phosphoramidate (Figure 2.N). The purpose of this modification was to overcome resistance in tumours deficient in dCK by delivering intracellulary a gemcitabine 5'-monophosphate, entering the cell by passive diffusion. ${ }^{126}$ In vitro tests on many cancer cell lines have shown that the prodrug is less active than native gemcitabine in wild-type cell lines but more active than native gemcitabine in dCK-deficient cell lines (AG6000 and CEM-dCK-). However, after 
blocking the equilibrative nucleoside transport, inhibition of tumour growth was no longer observed with the prodrug, indicating that the prodrug antitumour activity was mediated by cell entry implying equilibrative nucleoside transport.

\section{CONCLUSION}

Since the 90s, gemcitabine has become the standard treatment for pancreatic cancer. Studies show a therapeutic benefit from the use of gemcitabine compared to fluorouracil and have led to the prescription of gemcitabine as a standard treatment in advanced or metastatic pancreatic cancer. ${ }^{127}$ It is also widely used in combination for other solid cancers such as lung, bladder, ovary or breast.

It undergoes a series of phosphorylations to become active and thus brings the cell into apoptosis. However the rapid deamination after intravenous injection of gemcitabine induces the formation of its inactive metabolite ( $\mathrm{dFdU}$ ) which is then excreted, mainly in urine. Thus repeated injections and high concentrations to maintain a sufficient concentration for antitumour activity cause a number of side effects. ${ }^{40}$ Repeated exposition does not directly lead to clinical improvement. The current clinical are relies on a balance of anticancer activity vs. Toxicity to normal tissue, to achieve an efficient therapeutic scheme. The short half-life is not the only drawback: numerous tumours develop resistance mechanisms: resistance by a lack of transporters and resistance by a lack of kinase required for phosphorylation and thus activation. The chemical modification of a drug is a smart solution to try to override this resistance and improve the resulting pharmacokinetic parameters.

All changes at 4-( $M$-position with PEG, squalene, valproic acid and linear acyl derivatives (valeroyl, heptanoyl, lauroyl and stearoyl) have been characterised to protect the amine function and thus block CDA action. The enhanced bioavailability 
of prodrugs, thanks to the storage in various cytosolic fractions followed by a prolonged release, has been obtained by the addition of PEG, squalene in 4-( $(M)$ position and elaidic acid in 5' position. Increased plasma availability is also observed due to the encapsulation of lipophilic GemC18 in liposomes. An independent nucleoside transporter route can be observed with PEG, squalene, elaidic acid and derivatives, limiting the phenomenon of resistance. And finally, only the phosphoramidate function on $5^{\prime}$ position provides a mono-phosphate gemcitabine, initiating pathway activation.

In conclusion, gemcitabine prodrugs have beneficial antitumoural effects by using independent nucleoside transport, by reducing the catabolic effect of CDA, by prolonging the release of the native or mono-phosphate gemcitabine, and finally by enhancing the cytotoxicity effect. Gemcitabine modification seems to be an innovative and interesting approach to treat less-sensitive cancers.

\section{ACKNOWLEDGMENTS}

This work has been realized in the research program LYMPHOTERG financially supported by EuroNanoMed ERA-NET 09 and by Région Pays de la Loire. 


\section{References}

(1) Carmichael, J.; Fink, U.; Russell, R. C.; Spittle, M. F.; Harris, A. L.; Spiessi, G.; Blatter, J. Phase II study of gemcitabine in patients with advanced pancreatic cancer. Br. J. Cancer 1996, 73, 101-105.

(2) Hoang, T.; Kim, K.; Jaslowski, A.; Koch, P.; Beatty, P.; McGovern, J.; Quisumbing, M.; Shapiro, G.; Witte, R.; Schiller, J. H. Phase II study of second-line gemcitabine in sensitive or refractory small cell lung cancer. Lung Cancer 2003, 42, 97-102.

(3) Denise A., Y. Gemcitabine plus paclitaxel in breast cancer. Semin. Oncol. 2005, 32, 4 Supplement 6, S14-21.

(4) Ozols, R. F. Gemcitabine and carboplatin in second-line ovarian cancer. Semin. Oncol. 2005, 32, 4 Supplement 6, S4-8.

(5) Rauchwerger, D. R.; Firby, P. S.; Hedley, D. W.; Moore, M. J. Equilibrativesensitive nucleoside transporter and its role in gemcitabine sensitivity. Cancer Res. 2000, 60, 6075-6079.

(6) Farrell, J. J.; Elsaleh, H.; Garcia, M.; Lai, R.; Ammar, A.; Regine, W. F.; Abrams, R.; Benson, A. B.; Macdonald, J.; Cass, C. E.; Dicker, A. P.; Mackey, J. R. Human equilibrative nucleoside transporter 1 levels predict response to gemcitabine in patients with pancreatic cancer. Gastroenterology 2009, 136, 187-195.

(7) Duxbury, M. S.; Ito, H.; Zinner, M. J.; Ashley, S. W.; Whang, E. E. RNA interference targeting the M2 subunit of ribonucleotide reductase enhances pancreatic adenocarcinoma chemosensitivity to gemcitabine. Oncogene 2004, 23, $1539-1548$.

(8) Zacchigna, M.; Cateni, F.; Drioli, S.; Bonora, G. M. Multimeric, multifunctional derivatives of poly(ethylene glycol). Polymers 2011, 3, 1076-1090.

(9) Lundberg, B. B.; Risovic, V.; Ramaswamy, M.; Wasan, K. M. A lipophilic paclitaxel derivative incorporated in a lipid emulsion for parenteral administration. J. Control. Release 2003, 86, 93-100.

(10) Bergman, A. M.; Kuiper, C. M.; Voorn, D. A.; Comijn, E. M.; Myhren, F.; Sandvold, M. L.; Hendriks, H. R.; Peters, G. J. Antiproliferative activity and mechanism of action of fatty acid derivatives of arabinofuranosylcytosine in leukemia and solid tumor cell lines. Biochem. Pharmacol. 2004, 67, 503-511.

(11) Bianchi, V.; Borella, S.; Calderazzo, F.; Ferraro, P.; Chieco Bianchi, L.; Reichard, P. Inhibition of ribonucleotide reductase by 2'-substituted deoxycytidine analogs: possible application in AIDS treatment. Proc. Natl. Acad. Sci. U.S.A. 1994, $91,8403-8407$. 
(12) Stathis, A.; Moore, M. J. Advanced pancreatic carcinoma: current treatment and future challenges. Nat. Rev. Clin. Oncol. 2010, 7, 163-172.

(13) Eli Lilly and Company Gemzar (Gemcitabine HCL) for injection 2005.

(14) Eli Lilly and Company Annual Report and Proxy Statement 2010.

(15) Reid, J. M.; Qu, W.; Safgren, S. L.; Ames, M. M.; Krailo, M. D.; Seibel, N. L.; Kuttesch, J.; Holcenberg, J. Phase I trial and pharmacokinetics of gemcitabine in children with advanced solid tumors. J. Clin. Oncol. 2004, 22, 2445 -2451.

(16) Abbruzzese, J. L.; Grunewald, R.; Weeks, E. A.; Gravel, D.; Adams, T.; Nowak, B.; Mineishi, S.; Tarassoff, P.; Satterlee, W.; Raber, M. N. et al. A phase I clinical, plasma, and cellular pharmacology study of gemcitabine. J. Clin. Oncol. 1991, 9, 491-498.

(17) Griffith, D. A.; Jarvis, S. M. Nucleoside and nucleobase transport systems of mammalian cells. Biochim. Biophys. Acta 1996, 1286, 153-181.

(18) Paproski, R. J.; Ng, A. M.; Yao, S. Y.; Graham, K.; Young, J. D.; Cass, C. E. The role of human nucleoside transporters in uptake of 3'-deoxy-3'-fluorothymidine. Mol. Pharmacol. 2008, 74, 1372-1380.

(19) Ueno, H.; Kiyosawa, K.; Kaniwa, N. Pharmacogenomics of gemcitabine: can genetic studies lead to tailor-made therapy? Br. J. Cancer. 2007, 97, 145-151.

(20) Hodge, L. S.; Taub, M. E.; Tracy, T. S. Effect of its deaminated metabolite, 2',2'difluorodeoxyuridine, on the transport and toxicity of gemcitabine in HeLa cells. Biochem. Pharmacol. 2011, 81, 950-956.

(21) Mori, R.; Ishikawa, T.; Ichikawa, Y.; Taniguchi, K.; Matsuyama, R.; Ueda, M.; Fujii, Y.; Endo, I.; Togo, S.; Danenberg, P. V.; Shimada, H. Human equilibrative nucleoside transporter 1 is associated with the chemosensitivity of gemcitabine in human pancreatic adenocarcinoma and biliary tract carcinoma cells. Oncol. Rep. 2007, 17, 1201-1205.

(22) Giovannetti, E.; Del Tacca, M.; Mey, V.; Funel, N.; Nannizzi, S.; Ricci, S.; Orlandini, C.; Boggi, U.; Campani, D.; Del Chiaro, M.; Iannopollo, M.; Bevilacqua, G.; Mosca, F.; Danesi, R. Transcription analysis of human equilibrative nucleoside transporter-1 predicts survival in pancreas cancer patients treated with gemcitabine. Cancer Res. 2006, 66, 3928 -3935.

(23) Plunkett, W.; Huang, P.; Gandhi, V. Preclinical characteristics of gemcitabine. Anticancer Drugs 1995, 6, 7-13.

(24) Barton-Burke, M. Gemcitabine: a pharmacologic and clinical overview. Cancer Nurs. 1999, 22, 176-183. 
(25) Heinemann, V.; Xu, Y. Z.; Chubb, S.; Sen, A.; Hertel, L. W.; Grindey, G. B.; Plunkett, W. Cellular elimination of 2',2'-difluorodeoxycytidine 5'-triphosphate: a mechanism of self-potentiation. Cancer Res. 1992, 52, 533-539.

(26) Jansen, R. S.; Rosing, H.; Schellens, J. H. M.; Beijnen, J. H. Deoxyuridine analog nucleotides in deoxycytidine analog treatment: secondary active metabolites? Fundam. Clin. Pharmacol. 2011, 25, 172-185.

(27) Bergman, A. M.; Pinedo, H. M.; Peters, G. J. Determinants of resistance to 2', 2'difluorodeoxycytidine (gemcitabine). Drug Resist. Updat. 2002, 5, 19-33.

(28) Komori, S.; Osada, S.; Mori, R.; Matsui, S.; Sanada, Y.; Tomita, H.; Tokuyama, Y.; Takahashi, T.; Yamaguchi, K.; Yoshida, K. Contribution of thymidylate synthase to gemcitabine therapy for advanced pancreatic cancer. Pancreas 2010, 39, 12841292.

(29) Ruiz van Haperen, V. W.; Veerman, G.; Vermorken, J. B.; Peters, G. J. 2',2'Difluoro-deoxycytidine (gemcitabine) incorporation into RNA and DNA of tumour cell lines. Biochem. Pharmacol. 1993, 46, 762-766.

(30) Clarke, M. L.; Mackey, J. R.; Baldwin, S. A.; Young, J. D.; Cass, C. E. The role of membrane transporters in cellular resistance to anticancer nucleoside drugs. Cancer Treat. Res. 2002, 112, 27-47.

(31) Maréchal, R.; Mackey, J. R.; Lai, R.; Demetter, P.; Peeters, M.; Polus, M.; Cass, C. E.; Young, J.; Salmon, I.; Devière, J.; Van Laethem, J.-L. Human equilibrative nucleoside transporter 1 and human concentrative nucleoside transporter 3 predict survival after adjuvant gemcitabine therapy in resected pancreatic adenocarcinoma. Clin. Cancer Res. 2009, 15, 2913-2919.

(32) Santini, D.; Schiavon, G.; Vincenzi, B.; Cass, C. E.; Vasile, E.; Manazza, A. D.; Catalano, V.; Baldi, G. G.; Lai, R.; Rizzo, S.; Giacobino, A.; Chiusa, L.; Caraglia, M.; Russo, A.; Mackey, J.; Falcone, A.; Tonini, G. Human equilibrative nucleoside transporter 1 (hENT1) levels predict response to gemcitabine in patients with biliary tract cancer (BTC). Curr. Cancer Drug Targets 2011, 11, 123-129.

(33) Sebastiani, V.; Ricci, F.; Rubio-Viqueira, B.; Kulesza, P.; Yeo, C. J.; Hidalgo, M.; Klein, A.; Laheru, D.; lacobuzio-Donahue, C. A. Immunohistochemical and genetic evaluation of deoxycytidine kinase in pancreatic cancer: relationship to molecular mechanisms of gemcitabine resistance and survival. Clin. Cancer Res. 2006, 12, 2492-2497.

(34) Zhou, B. S.; Tsai, P.; Ker, R.; Tsai, J.; Ho, R.; Yu, J.; Shih, J.; Yen, Y. Overexpression of transfected human ribonucleotide reductase $M 2$ subunit in human cancer cells enhances their invasive potential. Clin. Exp. Metastasis 1998, 16, 43-49.

(35) Zhou, J.; Oliveira, P.; Li, X.; Chen, Z.; Bepler, G. Modulation of the ribonucleotide reductase-antimetabolite drug interaction in cancer cell lines. J. Nucleic Acids 2010, 2010:597098. 
(36) Fujita, H.; Ohuchida, K.; Mizumoto, K.; Itaba, S.; Ito, T.; Nakata, K.; Yu, J.; Kayashima, T.; Souzaki, R.; Tajiri, T.; Manabe, T.; Ohtsuka, T.; Tanaka, M. Gene expression levels as predictive markers of outcome in pancreatic cancer after gemcitabine-based adjuvant chemotherapy. Neoplasia 2010, 12, 807-817.

(37) Tolis, C.; Peters, G. .; Ferreira, C. G.; Pinedo, H. M.; Giaccone, G. Cell cycle disturbances and apoptosis induced by topotecan and gemcitabine on human lung cancer cell lines. Eur. J. Cancer 1999, 35, 796-807.

(38) Costantino, C. L.; Witkiewicz, A. K.; Kuwano, Y.; Cozzitorto, J. A.; Kennedy, E. P.; Dasgupta, A.; Keen, J. C.; Yeo, C. J.; Gorospe, M.; Brody, J. R. The role of HuR in gemcitabine efficacy in pancreatic cancer: HuR-upregulates the expression of the gemcitabine metabolizing enzyme deoxycytidine kinase. Cancer Res. 2009, 69, 4567-4572.

(39) Richards, N. G.; Rittenhouse, D. W.; Freydin, B.; Cozzitorto, J. A.; Grenda, D.; Rui, H.; Gonye, G.; Kennedy, E. P.; Yeo, C. J.; Brody, J. R.; Witkiewicz, A. K. HuR status is a powerful marker for prognosis and response to gemcitabine-based chemotherapy for resected pancreatic ductal adenocarcinoma patients. Ann. Surg. 2010, 252, 499-505, discussion 505-506.

(40) Storniolo, A. M.; Allerheiligen, S. R.; Pearce, H. L. Preclinical, pharmacologic, and phase I studies of gemcitabine. Semin. Oncol. 1997, 24, 2 Supplement 7, S7-27-7.

(41) Mero, A.; Clementi, C.; Veronese, F. M.; Pasut, G. Covalent conjugation of poly(ethylene glycol) to proteins and peptides: strategies and methods. Methods Mol. Biol. 2011, 751, 95-129.

(42) Pasut, G.; Veronese, F. M. State of the art in PEGylation: The great versatility achieved after forty years of research. J. Control. Release 2012, 161, 461-472.

(43) Pasut, G.; Veronese, F. M. PEG conjugates in clinical development or use as anticancer agents: An overview. Adv. Drug Deliv. Rev. 2009, 61, 1177-1188.

(44) Sawant, R. M. Polyethylene glycol (peg) as a key component of long-circulating delivery systems for therapy and imaging. Pharm. Sci. Dissert. 2008, 1-107.

(45) Caliceti, P.; Veronese, F. M. Pharmacokinetic and biodistribution properties of poly(ethylene glycol)-protein conjugates. Adv. Drug Deliv. Rev. 2003, 55, 12611277.

(46) Maeda, H.; Wu, J.; Sawa, T.; Matsumura, Y.; Hori, K. Tumor vascular permeability and the EPR effect in macromolecular therapeutics: a review. J. Control. Release 2000, 65, 271-284.

(47) Szebeni, J. Complement activation-related pseudoallergy: A new class of druginduced acute immune toxicity. Toxicology 2005, 216, 106-121. 
(48) Liu, J.; Zahedi, P.; Zeng, F.; Allen, C. Nano-sized assemblies of a PEGdocetaxel conjugate as a formulation strategy for docetaxel. J. Pharm. Sci. 2008, 97, 3274-3290.

(49) Li, C.; Yu, D.; Inoue, T.; Yang, D. J.; Milas, L.; Hunter, N. R.; Kim, E. E.; Wallace, $\mathrm{S}$. Synthesis and evaluation of water-soluble polyethylene glycol-paclitaxel conjugate as a paclitaxel prodrug. Anticancer Drugs 1996, 7, 642-648.

(50) Vandana, M.; Sahoo, S. K. Long circulation and cytotoxicity of PEGylated gemcitabine and its potential for the treatment of pancreatic cancer. Biomaterials 2010, 31, 9340-9356.

(51) Chuang, K.-H.; Wang, H.-E.; Chen, F.-M.; Tzou, S.-C.; Cheng, C.-M.; Chang, Y.C.; Tseng, W.-L.; Shiea, J.; Lin, S.-R.; Wang, J.-Y.; Chen, B.-M.; Roffler, S. R.; Cheng, T.-L. Endocytosis of PEGylated agents enhances cancer imaging and anticancer efficacy. Mol. Cancer Ther. 2010, 9, 1903-1912.

(52) Bareford, L. M.; Swaan, P. W. Endocytic mechanisms for targeted drug delivery. Adv. Drug Deliv. Rev. 2007, 59, 748-758.

(53) Pasut, G.; Canal, F.; Dalla Via, L.; Arpicco, S.; Veronese, F. M.; Schiavon, O. Antitumoral activity of PEG-gemcitabine prodrugs targeted by folic acid. J. Control. Release 2008, 127, 239-248.

(54) Basal, E.; Eghbali-Fatourechi, G. Z.; Kalli, K. R.; Hartmann, L. C.; Goodman, K. M.; Goode, E. L.; Kamen, B. A.; Low, P. S.; Knutson, K. L. Functional folate receptor alpha is elevated in the blood of ovarian cancer patients. PLOS ONE 2009, 4, e6292.

(55) Iwakiri, S.; Sonobe, M.; Nagai, S.; Hirata, T.; Wada, H.; Miyahara, R. Expression status of folate receptor alpha is significantly correlated with prognosis in non-smallcell lung cancers. Ann. Surg. Oncol. 2008, 15, 889-899.

(56) Hartmann, L. C.; Keeney, G. L.; Lingle, W. L.; Christianson, T. J.; Varghese, B.; Hillman, D.; Oberg, A. L.; Low, P. S. Folate receptor overexpression is associated with poor outcome in breast cancer. Int. J. Cancer 2007, 121, 938-942.

(57) Shmeeda, H.; Amitay, Y.; Gorin, J.; Tzemach, D.; Mak, L.; Ogorka, J.; Kumar, S.; Zhang, J. A.; Gabizon, A. Delivery of zoledronic acid encapsulated in folatetargeted liposome results in potent in vitro cytotoxic activity on tumor cells. J. Control. Release 2010, 146, 76-83.

(58) Yang, S.-J.; Lin, F.-H.; Tsai, K.-C.; Wei, M.-F.; Tsai, H.-M.; Wong, J.-M.; Shieh, M.-J. Folic acid-conjugated chitosan nanoparticles enhanced protoporphyrin IX accumulation in colorectal cancer cells. Bioconjug. Chem. 2010, 21, 679-689.

(59) Kaaki, K.; Herve, K.; Chiper, M.; Shkilnyy, A.; Soucé, M.; Benoit, R.; Paillard, A.; Dubois, P.; Saboungi, M.-L.; Chourpa, I. Magnetic nanocarriers of doxorubicin coated with poly(ethylene glycol) and folic acid: relation between coating structure, surface properties, colloidal stability and cancer cell targeting. Langmuir 2011, 28, 14961505. 
(60) Schiavon, O.; Pasut, G.; Moro, S.; Orsolini, P.; Guiotto, A.; Veronese, F. M. PEG-Ara-C conjugates for controlled release. Eur. J. Med. Chem. 2004, 39, 123133.

(61) Dauty, E.; Remy, J.-S.; Zuber, G.; Behr, J.-P. Intracellular delivery of nanometric DNA particles via the folate receptor. Bioconjug. Chem. 2002, 13, 831-839.

(62) Harris, J. M.; Chess, R. B. Effect of pegylation on pharmaceuticals. Nat. Rev. Drug Discov. 2003, 2, 214-221.

(63) Bender, D. M.; Bao, J.; Dantzig, A. H.; Diseroad, W. D.; Law, K. L.; Magnus, N. A.; Peterson, J. A.; Perkins, E. J.; Pu, Y. J.; Reutzel-Edens, S. M.; Remick, D. M.; Starling, J. J.; Stephenson, G. A.; Vaid, R. K.; Zhang, D.; McCarthy, J. R. Synthesis, crystallization, and biological evaluation of an orally active prodrug of gemcitabine. J. Med. Chem. 2009, 52, 6958-6961.

(64) Koolen, S. L.; Witteveen, P. O.; Jansen, R. S.; Langenberg, M. H.; Kronemeijer, R. H.; Nol, A.; Garcia-Ribas, I.; Callies, S.; Benhadji, K. A.; Slapak, C. A.; Beijnen, J. H.; Voest, E. E.; Schellens, J. H. Phase I study of oral gemcitabine prodrug (LY2334737) alone and in combination with erlotinib in patients with advanced solid tumors. Clin. Cancer Res. 2011, 17, 6071-6082.

(65) Huang, Z.-R.; Lin, Y.-K.; Fang, J.-Y. Biological and pharmacological activities of squalene and related compounds: potential uses in cosmetic dermatology. Molecules 2009, 14, 540-554.

(66) Kelly, G. S. Squalene and its potential clinical uses. Altern. Med. Rev. 1999, 4, 29-36.

(67) Newmark, H. L. Squalene, olive oil, and cancer risk: a review and hypothesis. Cancer Epidemiol. Biomarkers Prev. 1997, 6, 1101-1103.

(68) Couvreur, P.; Stella, B.; Reddy, L. H.; Hillaireau, H.; Dubernet, C.; Desmaële, D.; Lepêtre-Mouelhi, S.; Rocco, F.; Dereuddre-Bosquet, N.; Clayette, P.; Rosilio, V.; Marsaud, V.; Renoir, J.-M.; Cattel, L. Squalenoyl nanomedicines as potential therapeutics. Nano Lett. 2006, 6, 2544-2548.

(69) Desmaële, D.; Gref, R.; Couvreur, P. Squalenoylation: A generic platform for nanoparticular drug delivery. J.Control. Release 2012, 161, 609-618.

(70) Jordheim, L. P.; Cros, E.; Gouy, M.-H.; Galmarini, C. M.; Peyrottes, S.; Mackey, J.; Perigaud, C.; Dumontet, C. Characterization of a gemcitabine-resistant murine leukemic cell line: reversion on in vitro resistance by a mononucleotide prodrug. Clin. Cancer Res. 2004, 10, 5614-5621. 
(71) Gourdeau, H.; Clarke, M. L.; Ouellet, F.; Mowles, D.; Selner, M.; Richard, A.; Lee, N.; Mackey, J. R.; Young, J. D.; Jolivet, J.; Lafrenière, R. G.; Cass, C. E. Mechanisms of uptake and resistance to troxacitabine, a novel deoxycytidine nucleoside analogue, in human leukemic and solid tumor cell lines. Cancer Res. 2001, 61, 7217-7224.

(72) Reddy, L. H.; Dubernet, C.; Mouelhi, S. L.; Marque, P. E.; Desmaële, D.; Couvreur, P. A new nanomedicine of gemcitabine displays enhanced anticancer activity in sensitive and resistant leukemia types. J. Control. Release 2007, 124, 20 27.

(73) Réjiba, S.; Reddy, L. H.; Bigand, C.; Parmentier, C.; Couvreur, P.; Hajri, A. Squalenoyl gemcitabine nanomedicine overcomes the low efficacy of gemcitabine therapy in pancreatic cancer. Nanomedicine 2011, 7, 841-849.

(74) Pili, B.; Reddy, L. H.; Bourgaux, C.; Lepêtre-Mouelhi, S.; Desmaële, D.; Couvreur, P. Liposomal squalenoyl-gemcitabine: formulation, characterization and anticancer activity evaluation. Nanoscale 2010, 2, 1521-1526.

(75) Arias, J. L.; Reddy, L. H.; Othman, M.; Gillet, B.; Desmaële, D.; Zouhiri, F.; Dosio, F.; Gref, R.; Couvreur, P. Squalene based nanocomposites: a new platform for the design of multifunctional pharmaceutical theragnostics. ACS Nano 2011, 5, 1513-1521.

(76) Bildstein, L.; Dubernet, C.; Marsaud, V.; Chacun, H.; Nicolas, V.; Gueutin, C.; Sarasin, A.; Bénech, H.; Lepêtre-Mouelhi, S.; Desmaële, D.; Couvreur, P. Transmembrane diffusion of gemcitabine by a nanoparticulate squalenoyl prodrug: An original drug delivery pathway. J. Control. Release 2010, 147, 163-170.

(77) Podgorski, I.; Sloane, B. F. Cathepsin B and its role(s) in cancer progression. Biochem. Soc. Symp. 2003, 70, 263-276.

(78) Yang, Z.; Cox, J. L. Cathepsin L increases invasion and migration of B16 melanoma. Cancer Cell Int. 2007, 7, 8.

(79) Celia, C.; Cosco, D.; Paolino, D.; Fresta, M. Gemcitabine-loaded innovative nanocarriers vs GEMZAR: Biodistribution, pharmacokinetic features and in vivo antitumor activity. Expert Opin. Drug Deliv. 2011, 8, 1609-1629.

(80) Dosio, F.; Reddy, L. H.; Ferrero, A.; Stella, B.; Cattel, L.; Couvreur, P. Novel nanoassemblies composed of squalenoyl-paclitaxel derivatives: synthesis, characterization, and biological evaluation. Bioconjug. Chem. 2011, 21, 1349-1361.

(81) Jantscheff, P.; Ziroli, V.; Esser, N.; Graeser, R.; Kluth, J.; Sukolinskaya, A.; Taylor, L. A.; Unger, C.; Massing, U. Anti-metastatic effects of liposomal gemcitabine in a human orthotopic LNCaP prostate cancer xenograft model. Clin. Exp. Metastasis 2009, 26, 981-992. 
(82) Aggarwal, S.; Yadav, S.; Gupta, S. EGFR targeted PLGA nanoparticles using gemcitabine for treatment of pancreatic cancer. J. Biomed. Nanotechnol 2011, 7, 137-138.

(83) Yang, F.; Jin, C.; Yang, D.; Jiang, Y.; Li, J.; Di, Y.; Hu, J.; Wang, C.; Ni, Q.; Fu, D. Magnetic functionalised carbon nanotubes as drug vehicles for cancer lymph node metastasis treatment. Eur. J. Cancer 2011, 47, 1873-1882

(84) Ventura, C. A.; Cannavà, C.; Stancanelli, R.; Paolino, D.; Cosco, D.; La Mantia, A.; Pignatello, R.; Tommasini, S. Gemcitabine-loaded chitosan microspheres. Characterization and biological in vitro evaluation. Biomed. Microdevices 2011, 13, 799-807.

(85) Stella, B.; Arpicco, S.; Rocco, F.; Marsaud, V.; Renoir, J. M.; Cattel, L.; Couvreur, P. Encapsulation of gemcitabine lipophilic derivatives into polycyanoacrylate nanospheres and nanocapsules. Int. J. Pharm. 2007, 344, 71-77.

(86) Arya, G.; Vandana, M.; Acharya, S.; Sahoo, S. K. Enhanced antiproliferative activity of Herceptin (HER2)-conjugated gemcitabine-loaded chitosan nanoparticle in pancreatic cancer therapy. Nanomedicine 2011, 7, 859-870.

(87) Cattel, L.; Ceruti, M.; Dosio, F. From conventional to stealth liposomes: a new frontier in cancer chemotherapy. Tumori. 2003, 89, 237-249.

(88) Tardi, P.; Choice, E.; Masin, D.; Redelmeier, T.; Bally, M.; Madden, T. D. Liposomal Encapsulation of topotecan enhances anticancer efficacy in murine and human xenograft models. Cancer Res. 2000, 60, 3389-3393.

(89) Milla, P.; Dosio, F.; Cattel, L. PEGylation of proteins and liposomes: a powerful and flexible strategy to improve the drug delivery. Curr. Drug Metab. 2012, 13, 105109

(90) Immordino, M. L.; Brusa, P.; Rocco, F.; Arpicco, S.; Ceruti, M.; Cattel, L. Preparation, characterization, cytotoxicity and pharmacokinetics of liposomes containing lipophilic gemcitabine prodrugs. J. Control. Release 2004, 100, 331-346.

(91) Tokunaga, Y.; Iwasa, T.; Fujisaki, J.; Sawai, S.; Kagayama, A. Liposomal sustained-release delivery systems for intravenous injection. IV. Antitumor activity of newly synthesized lipophilic 1-beta-D-arabinofuranosylcytosine prodrug-bearing liposomes. Chem. Pharm. Bull. (Tokyo) 1988, 36, 3574-3583.

(92) Brusa, P.; Immordino, M. L.; Rocco, F.; Cattel, L. Antitumor activity and pharmacokinetics of liposomes containing lipophilic gemcitabine prodrugs. Anticancer Res. 2007, 27, 195-199.

(93) Sloat, B. R.; Sandoval, M. A.; Li, D.; Chung, W.-G.; Lansakara-P, D. S.; Proteau, P. J.; Kiguchi, K.; DiGiovanni, J.; Cui, Z. In vitro and in vivo anti-tumor activities of a gemcitabine derivative carried by nanoparticles. Int. J. Pharm. 2011, 409, 278-288. 
(94) Chung, W.-G.; Sandoval, M. A.; Sloat, B. R.; Lansakara-P, D. S.; Cui, Z. Stearoyl gemcitabine nanoparticles overcome resistance related to the overexpression of ribonucleotide reductase subunit M1. J. Control. Release 2012, 157, 132-140.

(95) Sandoval, M. A.; Sloat, B. R.; Lansakara-P., D. S.; Kumar, A.; Rodriguez, B. L.; Kiguchi, K.; DiGiovanni, J.; Cui, Z. EGFR-targeted stearoyl gemcitabine nanoparticles show enhanced anti-tumor activity. J. Control. Release 2012, 157, 287-296.

(96) Batrakova, E. V. Sensitizing of gemcitabine-resistant human leukemia cells by stearoyl gemcitabine nanoparticles. Nanomedecien (Lond.) 2011, 6, 1491-1492.

(97) Nicholson, R. I.; Gee, J. M.; Harper, M. E. EGFR and cancer prognosis. Eur. J. Cancer 2001, 37, S9-S15.

(98) Yokoyama, T.; Tam, J.; Kuroda, S.; Scott, A. W.; Aaron, J.; Larson, T.; Shanker, M.; Correa, A. M.; Kondo, S.; Roth, J. A.; Sokolov, K.; Ramesh, R. EGFR-targeted hybrid plasmonic magnetic nanoparticles synergistically induce autophagy and apoptosis in non-small cell lung cancer cells. PLoS ONE 2011, 6, e25507.

(99) Song, S.; Liu, D.; Peng, J.; Sun, Y.; Li, Z.; Gu, J.-R.; Xu, Y. Peptide ligandmediated liposome distribution and targeting to EGFR expressing tumor in vivo. Int. J. Pharm. 2008, 363, 155-161.

(100) Gao, J.; Yu, Y.; Zhang, Y.; Song, J.; Chen, H.; Li, W.; Qian, W.; Deng, L.; Kou, G.; Chen, J.; Guo, Y. EGFR-specific PEGylated immunoliposomes for active siRNA delivery in hepatocellular carcinoma. Biomaterials 2012, 33, 270-282.

(101) Benhabbour, S. R.; Luft, J. C.; Kim, D.; Jain, A.; Wadhwa, S.; Parrott, M. C.; Liu, R.; DeSimone, J. M.; Mumper, R. J. In vitro and in vivo assessment of targeting lipid-based nanoparticles to the epidermal growth factor-receptor (EGFR) using a novel Heptameric ZEGFR domain. J. Control. Release 2011, 158, 63-71.

(102) Bergman, A. M.; Adema, A. D.; Balzarini, J.; Bruheim, S.; Fichtner, I.; Noordhuis, P.; Fodstad, O.; Myhren, F.; Sandvold, M. L.; Hendriks, H. R.; Peters, G. $\mathrm{J}$. Antiproliferative activity, mechanism of action and oral antitumor activity of CP4126, a fatty acid derivative of gemcitabine, in in vitro and in vivo tumor models. Invest. New Drugs 2011, 29, 456-466.

(103) Adema, A. D.; Bijnsdorp, I. V.; Sandvold, M. L.; Verheul, H. M.; Peters, G. J. Innovations and opportunities to improve conventional (deoxy)nucleoside and fluoropyrimidine analogs in cancer. Curr. Med. Chem. 2009, 16, 4632-4643.

(104) Breistøl, K.; Balzarini, J.; Sandvold, M. L.; Myhren, F.; Martinsen, M.; De Clercq, E.; Fodstad, O. Antitumor activity of P-4055 (elaidic acid-cytarabine) compared to cytarabine in metastatic and s.c. human tumor xenograft models. Cancer Res. 1999, 59, 2944-2949.

(105) ELACYT Clinical Update - Clavis Pharma http://www.clavispharma.com/newsevents/2008-press-releases/elacyt-clinical-update (accessed Jan 4, 2012). 
(106) Dueland, S.; Aamdal, S.; Lind, M. J.; Thomas, H.; Sandvold, M. L.; Gaullier, J.M.; Rasch, W. Intravenous administration of CP-4055 (ELACYT) in patients with solid tumours. A Phase I study. Acta Oncol. 2009, 48, 137-145.

(107) Pignata, S.; Amant, F.; Scambia, G.; Sorio, R.; Breda, E.; Rasch, W.; Hernes, K.; Pisano, C.; Leunen, K.; Lorusso, D.; Cannella, L.; Vergote, I. A phase I-II study of elacytarabine (CP-4055) in the treatment of patients with ovarian cancer resistant or refractory to platinum therapy. Cancer Chemother. Pharmacol. 2011, 68, 1347-1353.

(108) Adema, A. D.; Smid, K.; Losekoot, N.; Honeywell, R. J.; Verheul, H. M.; Myhren, F.; Sandvold, M. L.; Peters, G. J. Metabolism and accumulation of the lipophilic deoxynucleoside analogs elacytarabine and CP-4126. Invest. New Drugs 2011 (Epub ahead of print).

(109) Galmarini, C. M.; Myhren, F.; Sandvold, M. L. CP-4055 and CP-4126 are active in ara-C and gemcitabine-resistant lymphoma cell lines. Br. J. Haematol. 2009, 144, $273-275$.

(110) Sandvold, M. L.; Galmarini, C.; Myhren, F.; Peters, G. The activity of the lipophilic nucleoside derivatives elacytarabine and CP-4126 in a panel of tumor cell lines resistant to nucleoside analogues. Nucleosides Nucleotides Nucleic Acids 2010, 29, 386-393.

(111) Gagnadoux, F.; Le Pape, A.; Urban, T.; Montharu, J.; Vecellio, L.; Dubus, J.-C.; Leblond, V.; Diot, P.; Grimbert, D.; Racineux, J.-L.; Lemarié, E. Safety of pulmonary administration of gemcitabine in rats. J. Aerosol Med. 2005, 18, 198-206.

(112) Adema, A. D.; Laan, A. C.; Myhren, F.; Fichtner, I.; Verheul, H. M.; Sandvold, M. L.; Peters, G. J. Cell cycle effects of fatty acid derivatives of cytarabine, CP-4055, and of gemcitabine, CP-4126, as basis for the interaction with oxaliplatin and docetaxel. Int. J. Oncol. 2010, 36, 285-294.

(113) Ali, S. M.; Khan, A. R.; Ahmad, M. U.; Chen, P.; Sheikh, S.; Ahmad, I. Synthesis and biological evaluation of gemcitabine-lipid conjugate (NEO6002). Bioorg. Med. Chem. Lett. 2005, 15, 2571-2574.

(114) Sakamoto, T.; Inoue, T.; Otomo, Y.; Yokomori, N.; Ohno, M.; Arai, H.; Nakagawa, Y. Deficiency of cardiolipin synthase causes abnormal mitochondrial function and morphology in germ cells of Caenorhabditis elegans. J. Biol. Chem. 2012, 287, 4590-4601.

(115) Chien, P.-Y.; Khan, A. R.; Miller, B.; Sheikh, S.; Ali, S. M.; Ahmad, M. U.; Ahmad, I. A novel gemcitabine-cardiolipin conjugate induced cytotoxicity in cancer cells through an equilibrative nucleoside transporter-independent pathway. AACR Meeting Abstracts 2005.

(116) Chen, P.; Chien, P.-Y.; Khan, A. R.; Sheikh, S.; Ali, S. M.; Ahmad, M. U.; Ahmad, I. In-vitro and in-vivo anti-cancer activity of a novel gemcitabine-cardiolipin conjugate. Anticancer Drugs 2006, 17, 53-61. 
(117) Galmarini, C. M.; Warren, G.; Senanayake, M. T.; Vinogradov, S. V. Efficient overcoming of drug resistance to anticancer nucleoside analogs by nanodelivery of active phosphorylated drugs. Int. J. Pharm. 2010, 395, 281-289.

(118) Bazzanini, R.; Manfredini, S.; Durini, E.; Gröschel, B.; Cinatl, J.; Balzarini, J.; De Clercq, E.; Imbach, J. L.; Périgaud, C.; Gosselin, G. Prodrugs of Ara-CMP and Ara-AMP with a S-acyl-2-thioethyl (SATE) biolabile phosphate protecting group: synthesis and biological evaluation. Nucleosides Nucleotides 1999, 18, 971-972.

(119) Tobias, S. C.; Borch, R. F. Synthesis and biological studies of novel nucleoside phosphoramidate prodrugs. J. Med. Chem. 2001, 44, 4475-4480.

(120) Perigaud, C.; Peyrottes, S.; Dumontet, C. Gemcitabine phosphoester prodrugs as anticancer agents. Patent Application WO/2009/053654 2009.

(121) Vande Voorde, J.; Liekens, S.; McGuigan, C.; Murziani, P. G.; Slusarczyk, M.; Balzarini, J. The cytostatic activity of NUC-3073, a phosphoramidate prodrug of 5fluoro-2'-deoxyuridine, is independent of activation by thymidine kinase and insensitive to degradation by phosphorolytic enzymes. Biochem. Pharmacol. 2011, $82,441-452$.

(122) McGuigan, C.; Madela, K.; Aljarah, M.; Gilles, A.; Brancale, A.; Zonta, N.; Chamberlain, S.; Vernachio, J.; Hutchins, J.; Hall, A.; Ames, B.; Gorovits, E.; Ganguly, B.; Kolykhalov, A.; Wang, J.; Muhammad, J.; Patti, J. M.; Henson, G. Design, synthesis and evaluation of a novel double pro-drug: INX-08189. A new clinical candidate for hepatitis C virus. Bioorg. Med. Chem. Lett. 2010, 20, 48504854.

(123) Vernachio, J. H.; Bleiman, B.; Bryant, K. D.; Chamberlain, S.; Hunley, D.; Hutchins, J.; Ames, B.; Gorovits, E.; Ganguly, B.; Hall, A.; Kolykhalov, A.; Liu, Y.; Muhammad, J.; Raja, N.; Walters, C. R.; Wang, J.; Williams, K.; Patti, J. M.; Henson, G.; Madela, K.; Aljarah, M.; Gilles, A.; McGuigan, C. INX-08189, a phosphoramidate prodrug of 6-O-methyl-2'-C-methyl guanosine, is a potent inhibitor of hepatitis $C$ virus replication with excellent pharmacokinetic and pharmacodynamic properties. Antimicrob. Agents Chemother. 2011, 55, 1843-1851.

(124) Tobias, S. C.; Borch, R. F. Synthesis and biological evaluation of a cytarabine phosphoramidate prodrug. Mol. Pharm. 2004, 1, 112-116.

(125) Mehellou, Y.; Valente, R.; Mottram, H.; Walsby, E.; Mills, K. I.; Balzarini, J.; McGuigan, C. Phosphoramidates of 2'- $\beta$-d-arabinouridine (AraU) as phosphate prodrugs; design, synthesis, in vitro activity and metabolism. Bioorg. Med. Chem. 2010, 18, 2439-2446.

(126) Wu, W.; Sigmond, J.; Peters, G. J.; Borch, R. F. Synthesis and biological activity of a gemcitabine phosphoramidate prodrug. J. Med. Chem. 2007, 50, 37433746. 
(127) Burris, H. A., 3rd; Moore, M. J.; Andersen, J.; Green, M. R.; Rothenberg, M. L.; Modiano, M. R.; Cripps, M. C.; Portenoy, R. K.; Storniolo, A. M.; Tarassoff, P.; Nelson, R.; Dorr, F. A.; Stephens, C. D.; Von Hoff, D. D. Improvements in survival and clinical benefit with gemcitabine as first-line therapy for patients with advanced pancreas cancer: a randomized trial. J. Clin. Oncol. 1997, 15, 2403-2413. 


\section{Figure captions}

Figure 1. Modification sites in gemcitabine molecule.

Figure 2. Chemicals representation of gemcitabine analogues and modification presented in this review. A: Deoxycytidine. B: Cytosine arabinoside (AraC): C: PEGgemcitabine. D: LY2334737. E: Folate-PEG-gemcitabine. F: Squalenoyl-gemcitabine. G: 4-(N)-acyl-gemcitabine. H: CP-4126. I: NEO6002. J: N-(n-butylamino)-O-(Spivaloyl-2-thioethyl)-O-5' gemcitabine phosphoramidate diester (Gem-1). K: N(isopropylamino)-O-(S-pivaloyl-2-thioethyl)-O-5'-gemcitabine phosphoramidate diester (Gem-2). L: N-(benzylamino)-O-(S-pivaloyl-2-thioethyl)-O-5'-gemcitabine phosphoramidate diester (Gem-3). M: N-(benzylamino)-O-(S-(2,2-dimethyl-3hydroxypropionyl)-2-thioethyl)-O-5'-gemcitabine phosphoramidate diester (Gem-4). N: $\quad$ 5'-(2'-Deoxy-2',2'-difluorocytidyl) 5-nitrofurfuryl $\quad N$-methyl- $N$-(4-chlorobutyl) phosphoramidate.

Figure 3. Kaplan-Meier survival curve..$^{13}$

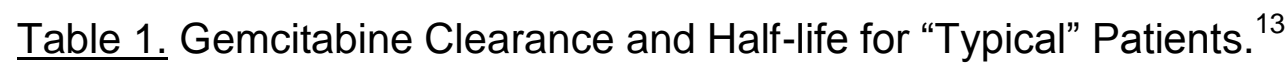

Figure 4. Phosphorylation and dephosphorylation of gemcitabine in the cell. ENTs: equilibrative nucleoside transporter, CNTs: concentrative nucleoside transporter, dFdCMP: gemcitabine monophosphate, dFdCDP: gemcitabine diphosphate, dFdCTP: gemcitabine triphosphate, dFdUMP: 2'-deoxy-2',2'-difluorouridine monophosphate, dFdU: 2', 2'- difluorodeoxyuridine, CDA: cytidine deaminase, DCTD: 
deoxycytidylate deaminase, 5'NT: 5'-nucleotidase, UMP/CMP kinase: nucleoside monophosphate kinase.

Figure 5. In vivo bioavailability of gemcitabine and PEGylated gemcitabine. The mice were divided in two groups. Equivalent concentration of gemcitabine and PEGylated gemcitabine $(6.74 \mathrm{mg} / \mathrm{kg})$ was given to group 1 and group 2, respectively. Gemcitabine and PEGylated gemcitabine were administered intravenously and blood was collected at different time intervals. Serum was separated and the concentration of gemcitabine was determined by RP-HPLC analysis, as described in materials and methods. $\quad\left({ }^{*}\right) p<0.005$ and $\quad\left(^{*}\right) p<0.05$ gemcitabine versus PEGylated gemcitabine. ${ }^{50}$

Figure 6. SQ-Gem improves inhibition of tumour growth and increased survival. (A) Mice $(n=8)$ bearing subcutaneous tumours were treated twice with Gem or SQ-Gem (20 mg/kg). After 1 month, statistical analysis of tumour volumes showed superior antitumour efficacy of SQ-Gem compared to untreated or SQ-treated mice ${ }^{* * *} P<$ 0.001) and to Gem $\left({ }^{\dagger} P<0.05,{ }^{\dagger} P<0.001\right)$. (B) The same experiment was performed on Panc1 orthotopic tumour model $(n=14)$. Tumours were significantly reduced by SQ-Gem treatment $\left({ }^{\star \star} P<0.01\right.$ vs. untreated mice and ${ }^{\dagger} P<0.05$ vs. Gem-treated mice). (C) Kaplan-Meier survival curves of orthotopic Panc1 tumour-bearing mice showed significant enhanced median survival after SQ-Gem treatment (vs. Gemtreated mice, $p<0.5$ and vs. control mice, $\left.{ }^{* * *} P<0.001\right) .{ }^{73}$

Figure 7. In vivo and ex vivo imaging of GemC18-NPs and PEG-GemC18-NPs. (A) IVIS images of athymic mice $24 \mathrm{~h}$ after injection of fluorescein-labeled GemC18-NPs 
or PEG-GemC18-NPs. (B) Relative fluorescence intensity values in BxPC-3 tumours (circular ROI in A). ${ }^{a} p=0.0006$, GemC18-NPs vs. PEG-GemC18-NPs. (C) Tissue distribution of fluorescein-labeled GemC18-NPs and PEG-GemC18-NPs $24 \mathrm{~h}$ after injection. ${ }^{b}$ GemC18-NPs vs. PEG-GemC18-NPs, $p=0.003,0.021$, and 0.002 for blood, liver, and spleen, respectively. ${ }^{93}$

Figure 8. Antitumour efficacy of CP-4126 as an oral drug in the human colon cancer xenograft Co6044. Mice treated with saline, qd 1-5 (ム), $100 \mathrm{mg} / \mathrm{kg} \mathrm{CP}-4126(\bullet)$, $20 \mathrm{mg} / \mathrm{kg} \mathrm{CP}-4126(\nabla)$ and $10 \mathrm{mg} / \mathrm{kg} \mathrm{CP}-4126(\square)$. The curve for the optimal schedule of gemcitabine (not shown) was in between that of the control and q3d schedule. (from ${ }^{102}$ ) 
Figures

Figure 1.

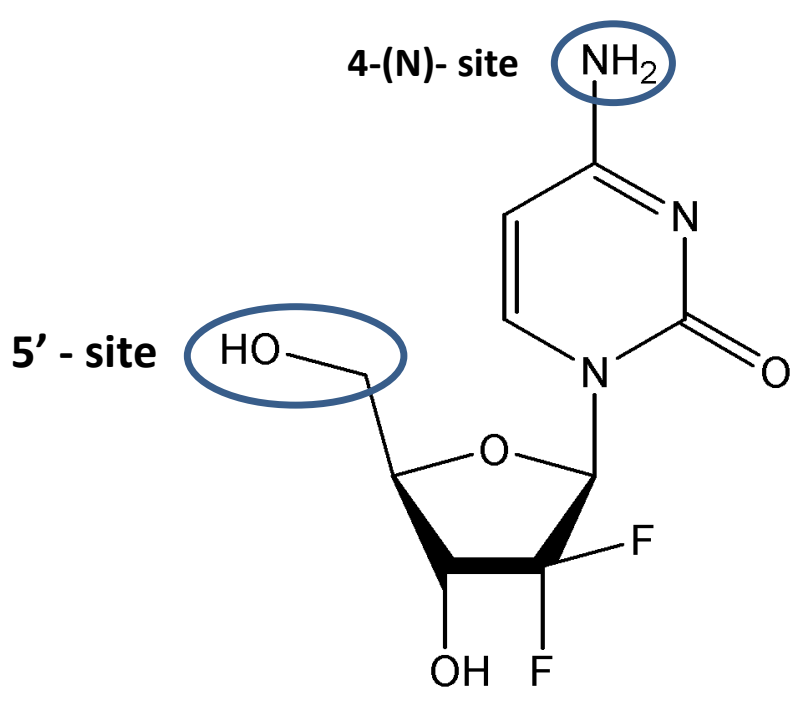


Figure 2.
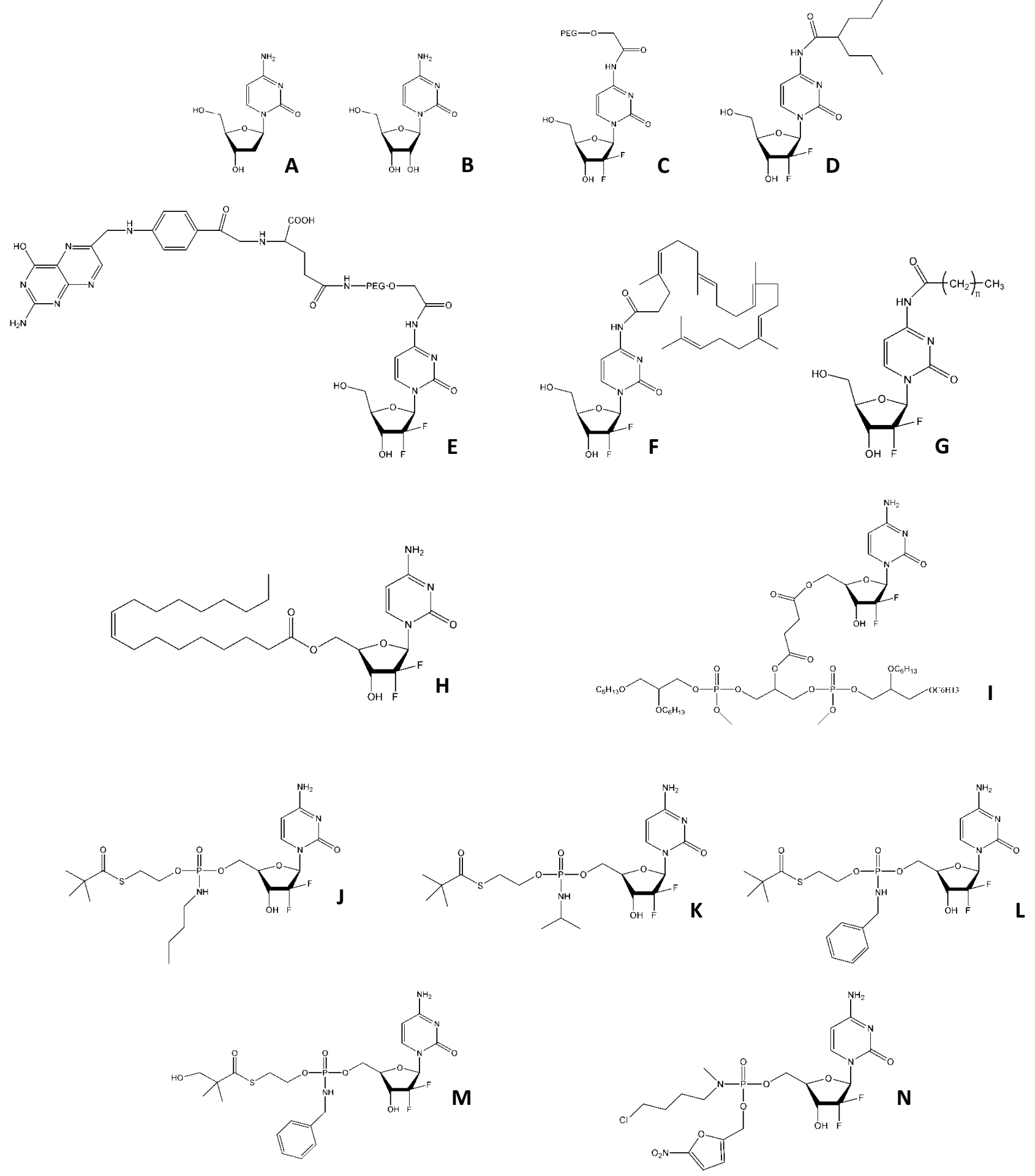
Figure 3.

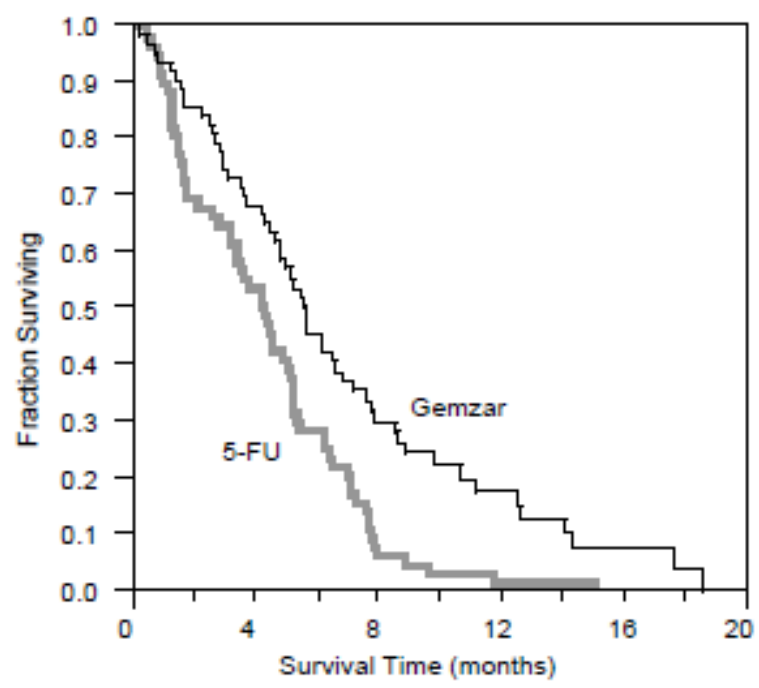


Table 1.

\begin{tabular}{c|c|c|c|c}
\hline Age & $\begin{array}{c}\text { Clearance } \\
\text { Men } \\
\left(\mathrm{L} / \mathrm{hr} / \mathrm{m}^{2}\right)\end{array}$ & $\begin{array}{c}\text { Clearance } \\
\text { Women } \\
\left(\mathrm{L} / \mathrm{hr} / \mathrm{m}^{2}\right)\end{array}$ & $\begin{array}{c}\text { Half-Life }^{\mathrm{a}} \\
\text { Men } \\
(\mathrm{min})\end{array}$ & $\begin{array}{c}\text { Half-Life }^{\mathrm{a}} \\
\text { Women } \\
(\mathrm{min})\end{array}$ \\
\hline 29 & 92.2 & 69.4 & 42 & 49 \\
45 & 75.7 & 57.0 & 48 & 57 \\
65 & 55.1 & 41.5 & 61 & 73 \\
79 & 40.7 & 30.7 & 79 & 94 \\
\hline
\end{tabular}

${ }^{a}$ Half-life for patients receiving a short infusion ( $\left.<70 \mathrm{~min}\right)$ 
Figure 4.

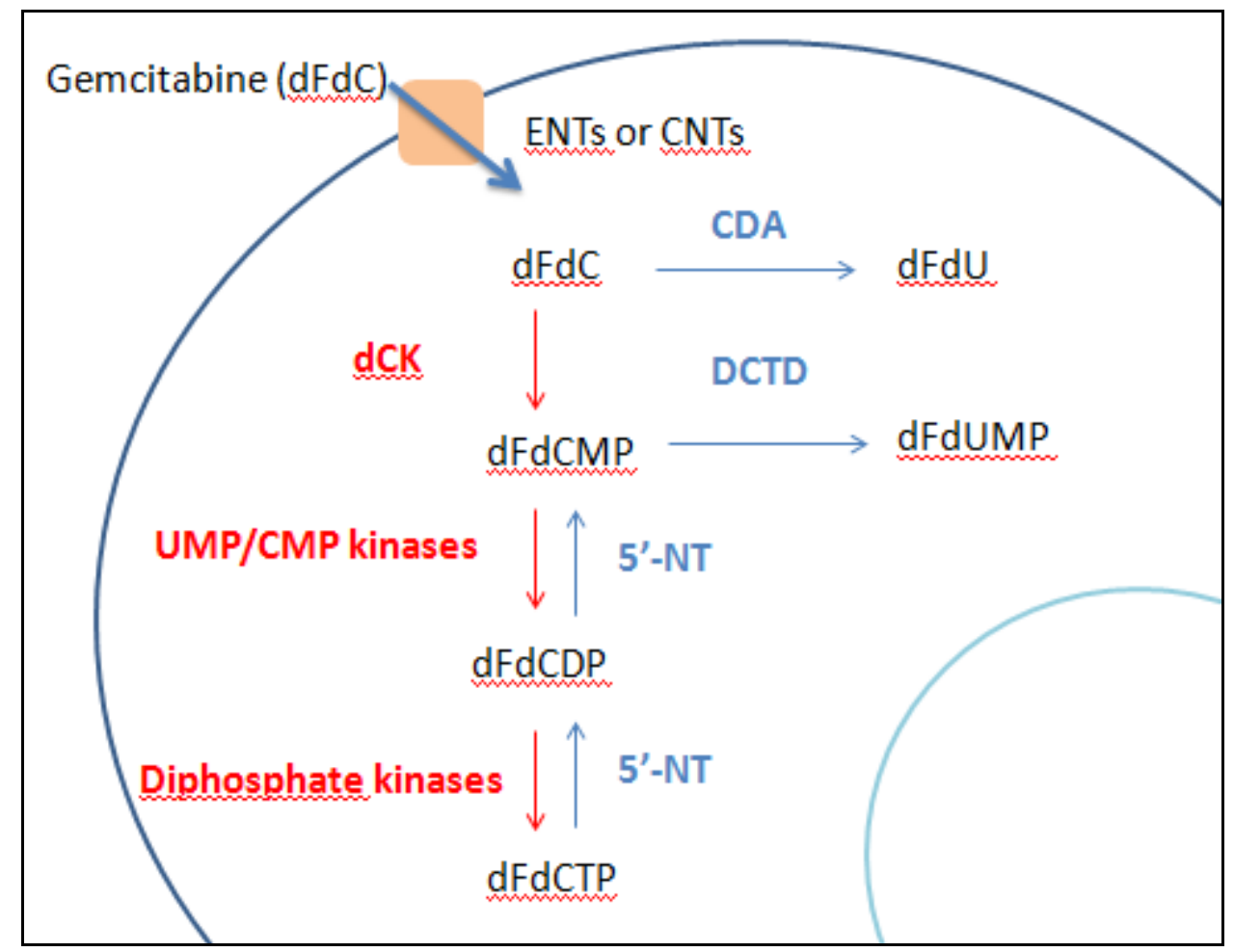


Figure 5.

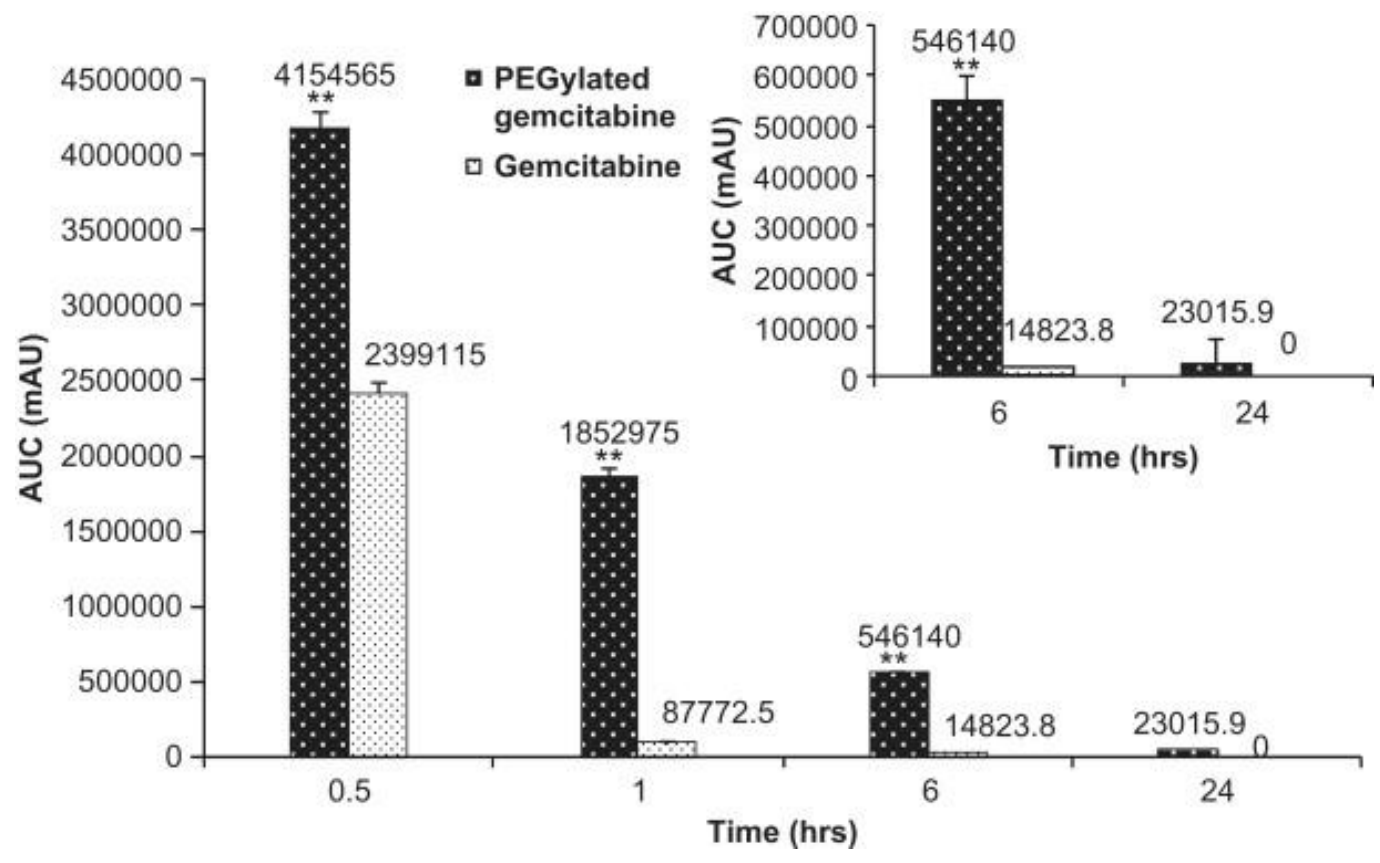


Figure 6.

A

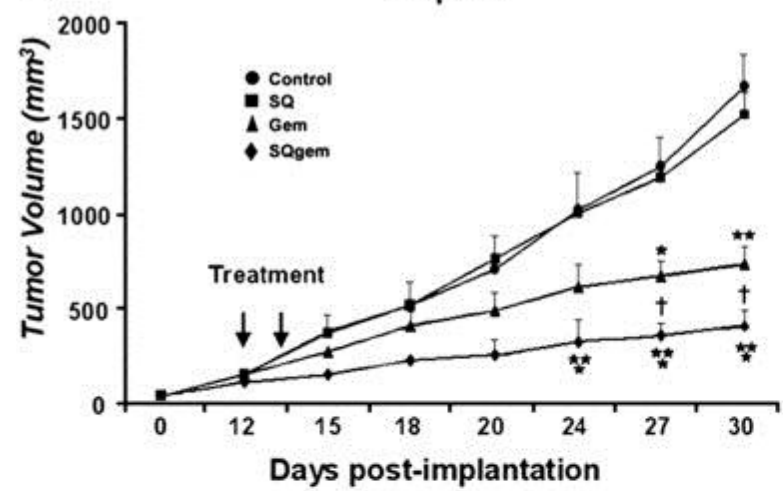

B

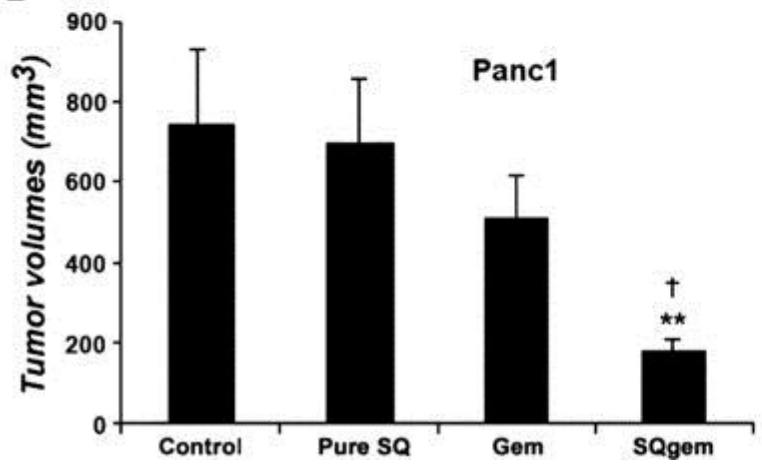

Panc1

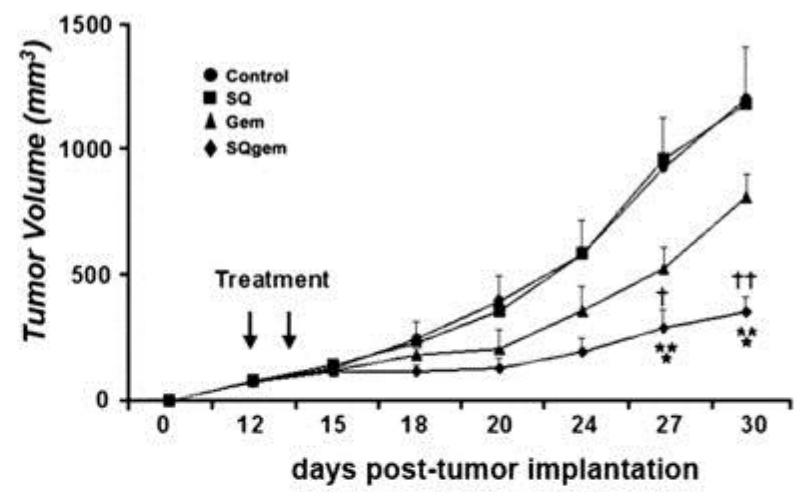

C

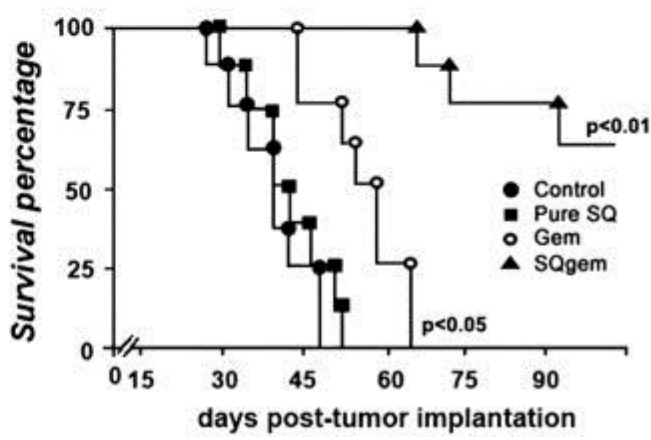


Figure 7.
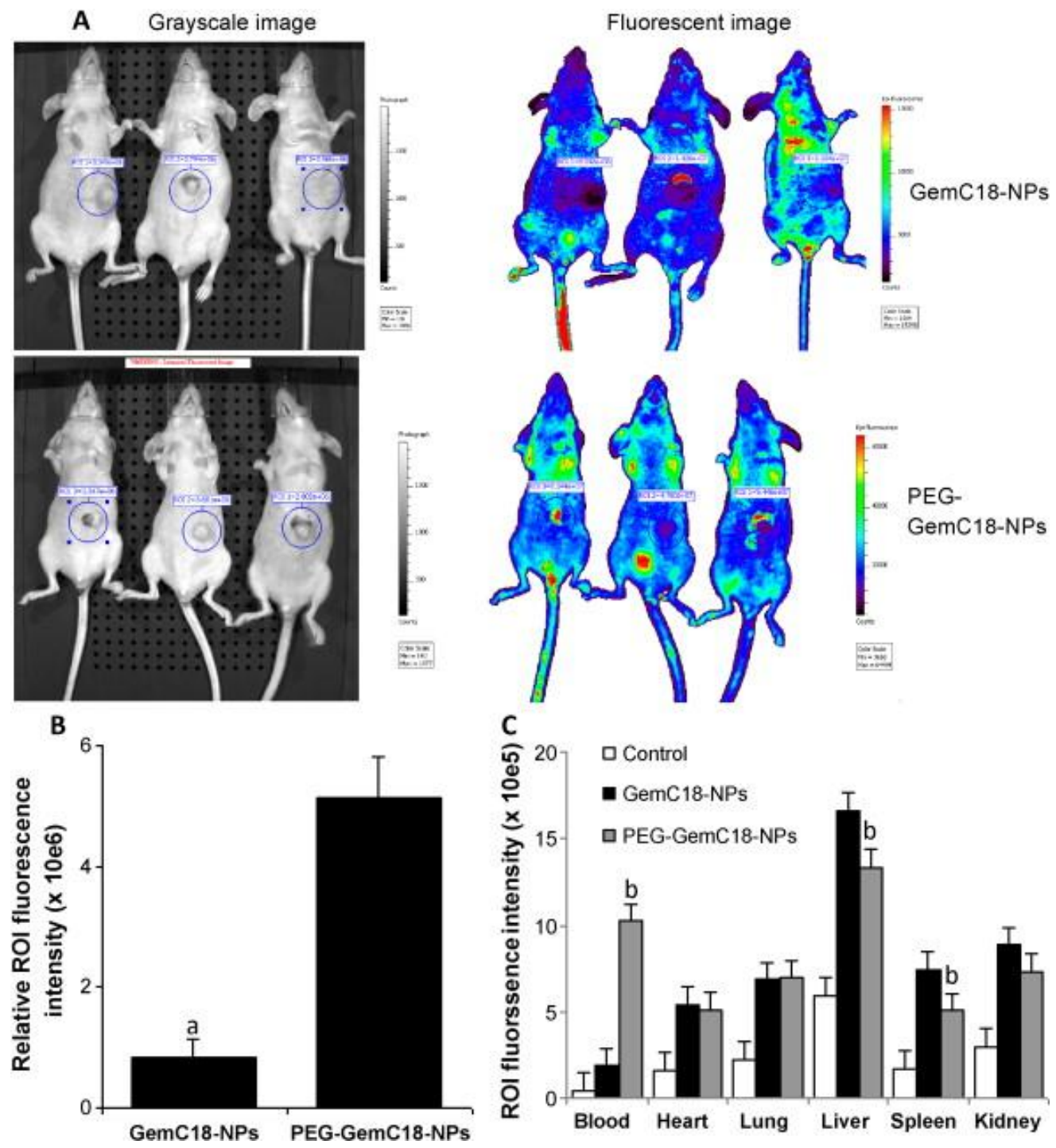
Figure 8.

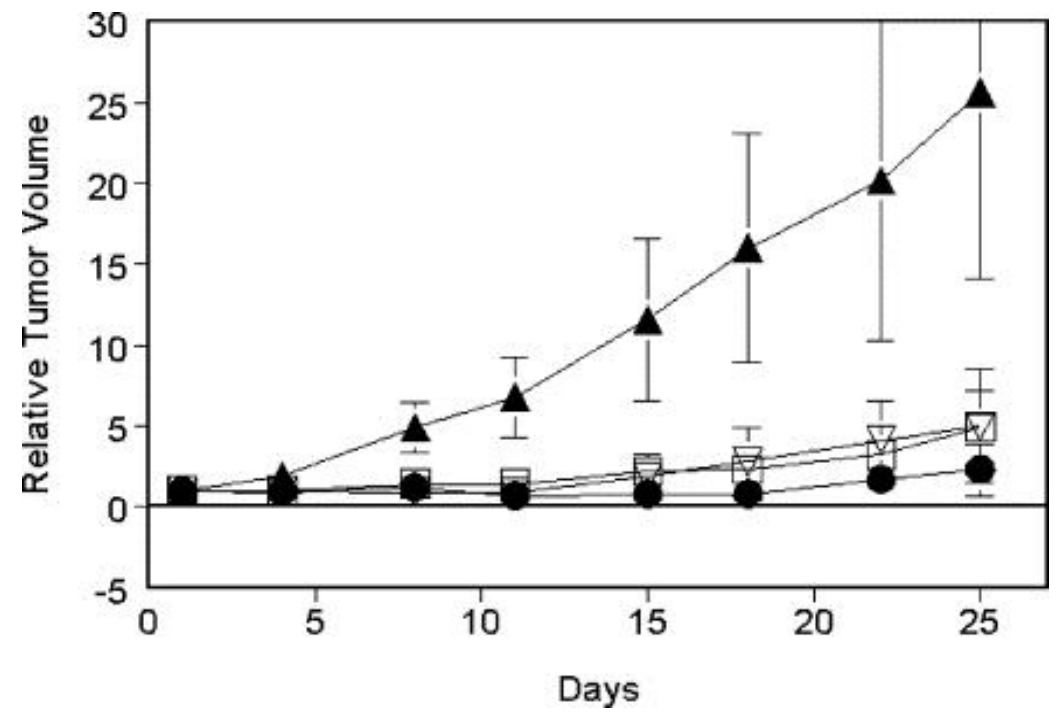

